\title{
Herramientas jurídicas para la aplicación de la perspectiva de género a la regulación de las cooperativas y otras entidades de la economía social
}

\author{
María José Senent Vidal \\ Profesora T. U. de Derecho Mercantil \\ Universitat Jaume I
}

Recibido: 10-01-2019

Aceptado: 12-02-2019

\begin{abstract}
Sumario: Introducción. 1. Diagnosticar la realidad. Datos, estadísticas e indicadores, actualizados. Los Informes sobre impacto de género. 2. Expresar y desarrollar el mandato constitucional de la igualdad de trato y de oportunidades y de eliminación de discriminaciones y desigualdades. 3. Promover la presencia equilibrada. 3.1. Eliminar barreras al acceso a la condición de socia y a la participación en igualdad en la actividad cooperativizada. La titularidad compartida. 3.2. Fomentar las políticas de conciliación/corresponsabilidad. 3.3. Alcanzar la presencia equilibrada en los órganos de gobierno y representación. 4. Combatir la brecha salarial y la retributiva. 5. Erradicar y prevenir la violencia de género en la actividad económica. 6. Promover la comunicación inclusiva. Bibliografía.
\end{abstract}

Resumen: Las entidades de la economía social son potencialmente idóneas para la adopción de medidas de acción positiva que faciliten la igualdad entre mujeres y hombres. Sus principios y valores incluyen una vocación explícita de igualdad y de interés social; además, su estructura participativa y flexible podría favorecer la presencia y participación en ellas de mujeres. Sin embargo, se ha constatado reiteradamente que el entorno económico, social y cultural en el que se desenvuelven las organizaciones de economía social influye decisivamente en el mantenimiento en su seno de situaciones de desigualdad en perjuicio de las mujeres. En este trabajo reflexionamos sobre tales inequidades y cómo el derecho puede ayudar a combatirlas.

Palabras clave: Cooperativas, Economía social, Género, Derecho.

Abstract: The social economy entities are potentially suitable for taking positive measures to facilitate equality between women and men. Its principles and values include an explicit aim of equality and social interest; In addition, its participatory and flexible structure could encourage the presence and participation in women. However, it has been repeatedly noted that the economic, social and cultural environment in which social economy organizations operate has a decisive influence on the maintenance of situations of inequality to the detriment of women. In this paper we reflect on such inequities and how the law can help fight them.

Keywords: Cooperatives; Social Economy; Gender; Law. 


\section{Introducción}

Por distintas vías, la lucha por conseguir la igualdad efectiva de mujeres y hombres ha dado en los últimos meses un salto cualitativo (tanto, que se habla ya de una "cuarta ola» del movimiento feminista), haciendo que se multiplique la demanda de reflexión teórica al respecto. Esto es especialmente importante a fin de consolidar lo conseguido y avanzar en los retos pendientes, ya que la teoría feminista que durante décadas ha explicado y sustentado tales avances no es siempre fácil de comprender y divulgar. Tanto más en el actual contexto de reacción y ataque a los derechos adquiridos, en el que se ha acabado "viralizando» la famosa frase de Simone de Beauvoir: «Nunca olvides que basta con una crisis política, económica o religiosa para que los derechos de las mujeres sean cuestionados. Esos derechos no son permanentes. Tendrás que mantenerte vigilante durante toda tu vida».

Ahora, que finalmente comienza a aceptarse de forma generalizada que hay que parar atención a la situación de desigualdad y de discriminación de las mujeres y adoptar medidas para su erradicación, es momento no sólo de constatar los detalles de la situación actual sino también de preparar las herramientas, en nuestro caso jurídicas, para el cambio. En las líneas que siguen sintetizaremos nuestras reflexiones al respecto en relación con el uso del derecho para la consecución de la igualdad real en un ámbito concreto, el de las cooperativas y otras entidades de la economía social.

Para ello, debemos tener presente, por una parte, que cuando hablamos de la regulación jurídica de las entidades de la economía social nos referimos a las normas emanadas de los poderes públicos (leyes, reglamentos, decretos, directivas, órdenes, resoluciones...); pero que también hay que tener en cuenta las normas con las que se dotan las propias organizaciones (estatutos sociales, reglamentos de régimen interno, acuerdos sociales...). Y que además en las últimas décadas ha ido extendiéndose la práctica de elaborar otro tipo de normas, de soft law, de carácter no obligatorio (planes de igualdad, memorias de sostenibilidad, códigos de gobierno corporativo, códigos éticos, planes de responsabilidad social empresarial...) en las que pueden irse introduciendo objetivos alcanzables por las organizaciones que las suscriben.

Por otra parte, como es sabido, cuando hablamos de género no nos referimos a las diferencias sexuales de origen biológico entre hombres y mujeres; nos referimos a cómo, en base a esas diferencias, se ha ido construyendo, social y culturalmente, lo que se considera «lo femenino» y «lo masculino» en cada momento histórico y en cada ámbito 
social ${ }^{1}$. Un enfoque de género sobre cualquier disciplina supone analizar cómo en ella «esas definiciones legitimadas de «lo femenino» y «lo masculino» influyen, regulan, o determinan formas de relación social entre los varones y las mujeres que se caracterizan por una distribución desigual de espacios de poder a partir de una prescripción de roles diferenciados - percibidos como hecho «natural» y destino inevitable—» (Pousada, 2003:10).

Frente a tales estereotipos, «la perspectiva de género es una herramienta o mecanismo de análisis que busca explicar el fenómeno de la desigualdad y de la inequidad entre hombres y mujeres»; porque solo "cuando se reconozca que hombres y mujeres somos diferentes, pero con los mismos derechos y las mismas oportunidades, sólo entonces la perspectiva de género estará destinada a desaparecer» (Staff, 2000: 3 y 6). Y es que «el problema de género no es un «problema de mujeres» sino que compromete tanto a hombres como a mujeres, porque lo que está legitimado es que la diferencia, (lo considerado «diferente») puede dar lugar a desigualdad de derechos. Lo que está legitimado son espacios de subordinación y de discriminación. Entonces no es un problema de mujeres» (Pousada, en Vázquez y Pousada, 2002:437). Y, como también se ha dicho, "cada vez es más difícil ser hombre en un mundo dominado por las mentalidades de algunos hombres. Este puede ser el segundo aspecto que nos puede llevar a colaborar en una nueva perspectiva de relaciones entre los géneros; porque la sociedad patriarcal no sólo afecta a las mujeres: está afectando a toda la humanidad. Nos afecta en lo personal y en lo social» (Pérez, 1996²).

1 «Si nosotros rastreamos desde lo legal cómo se fue construyendo la identidad de las mujeres, vemos que en todas las leyes que se dictaron en nuestro país durante el último siglo y en los debates parlamentarios previos, la mujer era definida con los atributos considerados femeninos por el imaginario social de la época. Y que la mayoría de los que participaron en el dictado de esas leyes eran hombres, ya que hasta mediados de siglo no había representación de legisladoras en el Parlamento. Nos dibujaron los hombres. Dibujaron nuestras necesidades, y las respuestas a nuestras necesidades. En la actualidad cambiaron un poco las cosas, las leyes son un poco distintas. Pero esto que se instaló como estereotipo de qué es ser mujer y qué es ser hombre, persiste más allá de las leyes que hayan logrado conquistas en ese sentido. Lo que persiste es el estereotipo, como este lugar marcado a la mujer y al hombre, sin reflexionar críticamente que no es un lugar natural, sino un lugar adjudicado. Si realmente es un lugar que nos corresponde o que podemos cambiar. El tema es ver cómo estos estereotipos persisten y operan, no sólo en el exterior sino en nuestro interior», Pousada, en Vázquez y Pousada, 2000:425.

2 Ver Arwa MAHDAWI, «Los psicológos estadounidenses advierten de que la masculinidad tradicional es perjudicial para la salud», eldiario.es, 17/01/19, https:// www.eldiario.es/theguardian/psicologos-estadounidenses-masculinidad-tradicionalperjudicial_0_857065008.html, 18/01/19, 12:56. 
Afecta también a las entidades de la economía social. Tales empresas son, no cabe duda, potencialmente idóneas para la adopción de medidas de acción positiva que faciliten la igualdad entre mujeres y hombres (Sajardo y Bakaikoa, 2004:7; Senent, 2007:10; Hernández, 2012:304 y 305). Por una parte, sus principios y valores incluyen una vocación explícita de igualdad y de interés social; por otra, su estructura participativa y flexible podría favorecer la presencia y participación en ellas de mujeres ${ }^{3}$. Y sin embargo, se ha constatado reiteradamente que el entorno económico, social y cultural en el que se desenvuelven las organizaciones de economía social influye decisivamente en el mantenimiento en su seno de situaciones de desigualdad en perjuicio de las mujeres. Como se ha indicado, "a pesar de que la participación y aporte de las mujeres al cooperativismo ha sido desde su inicio significativa en número y calidad, ha resultado más fuerte la organización social patriarcal que las buenas intenciones plasmadas en los principios cooperativos» (Granser, citado en Pousada, 2003:21). Ya en 2001, Delso refería cómo, aunque «la presencia de las mujeres en el empleo cooperativo es muy superior a la participación femenina en otras formas de empleo [...] En el resto de las situaciones (tipo de contrato, estabilidad en el empleo...) las mujeres socias y trabajadoras de cooperativas encuentran las mismas dificultades que sus homólogas en otras empresas», señalando la existencia de barreras a la condición de socias, que sus formas de contratación son más precarias (temporal y a tiempo parcial), y que existe segregación horizontal y vertical ${ }^{4}$. Veamos cómo se concretan tales inequidades y cómo el derecho puede ayudar a combatirlas.

3 Se han señalado, por ejemplo, como ventajas particulares, que la forma jurídica cooperativa aporta a las mujeres "una estrategia educativa» que les posibilita adquirir nuevas competencias y aptitudes; "un medio para lograr la satisfacción de necesidades básicas de ellas y de sus familias», proporcionándoles una cierta seguridad en el empleo, la posibilidad de participar directamente de los excedentes generados y unas mejores condiciones de trabajo (compatibilidad laboral y personal, flexibilidad, trabajo en equipo...); y «una estrategia organizativa» que les permite adquirir «mayor poder de decisión y aumentar su status social» (Ulshoefer, 1991:2). Ver al respecto el estudio de Esteban, Gargallo y Pérez, 2016: "se observa que la autogestión permite mayor flexibilidad que otras fórmulas empresariales, en aspectos como la conciliación o las condiciones laborales. Así mismo, las mujeres reconocen que su implicación con la entidad debe ser mayor, dado que su futuro laboral depende de la supervivencia de la cooperativa».

4 Para una breve definición de los conceptos de segregación horizontal y vertical ver, p. e., http://www.surt.org/maletaintercultural/index.php?vlg=0\&vmd=0\&vtp=0\&vit= 4\&tex=20, 22/01/19, 11:49. 


\section{Diagnosticar la realidad. Datos, estadísticas e indicadores, actualizados. Los Informes sobre impacto de género}

Desde nuestros primeros escritos en materia de Economía social y Género venimos señalando la necesidad de contar con información actualizada y completa de la situación de las mujeres en el sector de la economía social, a fin de conocer el verdadero alcance de la desigualdad; porque la realidad es que los datos desagregados por sexo, cuando existen, son insuficientes e incompletos, además de carecer frecuentemente de actualización. Así, en España, los datos más actualizados con los que contamos son los que suministra el Ministerio de Empleo y Seguridad Social sobre "Características de los Trabajadores de la Economía Social, en situación de alta en la Seguridad Social» ${ }^{5}$. Pero tales datos, extraídos de las cotizaciones al Régimen de Seguridad social de toda clase de cooperativas y sociedades laborales, mezclan e impiden discriminar los datos correspondientes a personas socias y a trabajadoras por cuenta ajena, no socias; tampoco permiten conocer separadamente los datos relativos a quienes trabajan en cada tipo de cooperativa (de trabajo asociado, agrarias, de crédito, de consumo...) o sociedad laboral; y no incluye información respecto de otras entidades de la economía social: asociaciones, fundaciones, empresas de inserción, centros especiales de empleo, cofradías de personas pescadoras y sociedades agrarias de transformación no parecen tener datos accesibles sobre sus integrantes, cuanto menos desagregados por sexo. Mucho menos constatables (si no es mediante trabajos específicos y, por lo general, mediante muestras reducidas) son los datos relativos a presencia de las mujeres en los órganos de representación y gestión, a cuáles son sus retribuciones, su formación y su situación personal y familiar, en qué condiciones realizan aportaciones económicas, cómo concilian...

En efecto, solamente algunos estudios, con algún desfase temporal ya y frecuentemente sectoriales (ver, para cooperativas agrarias, Carretero y Avello, 20116; y para cooperativas de trabajo asociado, COCETA,

5 http://www.empleo.gob.es/es/sec_trabajo/autonomos/economia-soc/Economia Social/estadisticas/CaracteristicasTrabajadores/index.htm, 22/01/19, 11:51.

6 Como excepción al desfase temporal, para las agrarias, un trabajo más general de Meliá, Carnicer y Juliá, de 2018, incluye (pp. 95 a 98) un breve análisis de las mujeres en puestos de responsabilidad en las cooperativas agroalimentarias españolas. Otros estudios se han publicado en los últimos meses (ver el apartado de Bibliografía), que no hacen sino corroborar el creciente interés en la materia y hacer todavía más patente la necesidad de datos generales, completos, actualizados y fiables. 
2004; FEVECTA, 2003), abordan temas tan significativos en relación con la igualdad de mujeres y hombres como su acceso a la condición de personas socias, su participación en los órganos de representación y dirección, sus retribuciones por los diferentes conceptos, las medidas que en su caso adoptan las cooperativas para favorecer la conciliación.... Y aun así, con todas las salvedades señaladas, de tales datos puede deducirse claramente la existencia y persistencia de la desigualdad también en el ámbito de la Economía social. Enunciaremos a continuación únicamente algunos ejemplos.

De los citados datos desagregados por sexo que aporta el Ministerio de Empleo español respecto de las personas que trabajan en cooperativas y sociedades laborales, al cruzarlos con sus categorías profesionales se infiere la denominada segregación vertical, esto es, que la promoción profesional de las mujeres también se ve frenada en las entidades de la Economía social.

Así, entre las personas tituladas superiores que trabajan en cooperativas y sociedades laborales, se ha alcanzado en 2018 prácticamente la paridad de mujeres y hombres, pero tal dato no se corresponde con los de personas egresadas de la enseñanza universitaria, donde desde hace ya un tiempo son claramente mayoritarias las mujeres ${ }^{7}$; en cambio, si observamos la categoría de personal diplomado universitario encontramos, "sorprendentemente», que el número de mujeres casi dobla al de hombres. Si las mujeres son mayoritarias al salir de la universidad, su presencia debería ser varios puntos mayor que la de los hombres en las cooperativas y sociedades laborales, en ambas categorías laborales. Su igualdad en la primera y su abrumadora presencia en la segunda refleja, por una parte, los obstáculos que todavía encuentran las mujeres para acceder a los trabajos mejor valorados, económica y socialmente; $y$, por otra, que, muy probablemente, mujeres capacitadas para ejercer tareas de superior clasificación profesional están siendo relegadas a las peor pagadas. Y el patrón se repite para las categorías profesionales administrativas, donde la presencia de mujeres es claramente mayoritaria entre las auxiliares administrativas y va disminuyendo para las de oficiales y jefes; y también entre oficiales de 1. ${ }^{\mathrm{a}}$ y 2. ${ }^{\mathrm{a}}$, de 3. ${ }^{a}$ y personal «subordinado» y «no cualificado». También se puede constatar la mayor precariedad de la prestación de trabajo de las muje-

7 Los últimos datos publicados en la Estadística de Estudiantes Universitarios (EEU) para el Curso 2017-2018 indican que «las mujeres representan el 55,1\% de los estudiantes de Grado y Primer y Segundo Ciclo» y que entre las personas egresadas son el $59,5 \%$; son el 54,8\% del estudiantado de Master, y únicamente en los estudios de Doctorado se da una situación prácticamente paritaria con los hombres. 
res en cooperativas y sociedades laborales: son mayoría entre las personas con contratos temporales; y aproximadamente $2 / 3$ de las que trabajan a tiempo parcial.

Todo ello nos lleva a reiterar la necesidad de obtener datos desagregados por sexo, completos y actualizados, de las personas socias y trabajadoras en las entidades de la Economía social. Sin ellos, las medidas que eventualmente puedan adoptarse para superar las situaciones de desigualdad presentes serán menos eficaces. A este respecto se ha de recordar, nuevamente, que el artículo 20 de la Ley Orgánica 3/2007, de 22 de marzo, para la igualdad efectiva de mujeres y hombres (LOIEMH) contiene el mandato a los poderes públicos de la inclusión sistemática de la variable de sexo en las estadísticas, encuestas y recogidas de datos que lleven a cabo; el establecimiento, en su caso, de nuevos indicadores; la realización de muestras suficientemente amplias; y la explotación de los datos disponibles.

Otro aspecto en el que cabe incidir a fin de aportar diagnósticos sobre la situación de las mujeres en la economía social es el de la necesaria realización de Informes de impacto de género. En España, los proyectos legislativos, antes de su tramitación parlamentaria, han de incorporar un «informe sobre su impacto por razón de género», en el que se deberían analizar y valorar sus eventuales efectos desde la perspectiva de la eliminación de desigualdades y de consecución de igualdad de oportunidades y de trato entre mujeres y hombres. Dicho informe debe incluir, en todo caso, entre otros aspectos, la identificación de los objetivos en materia de igualdad de oportunidades; la descripción de la situación de partida, la previsión de resultados y la valoración del eventual impacto de género; las medidas para corregir desigualdades o reforzar la igualdad; y las recomendaciones para la aplicación de la norma y el desarrollo de medidas complementarias.

Pero si bien es cierto que los textos legislativos, sean reguladores de entidades de economía social o no, van incorporando algunas medidas de fomento de la igualdad, también lo es que no se suele cumplir el mandato de realizar, previamente, un verdadero informe de impacto de género. En efecto, se ha denunciado reiteradamente «que en muchos casos no se han realizado los informes preceptivos o que éstos se han limitado a indicar la no pertinencia de género de normas concretas (Alonso, Diz y Lois, 2010:109, citando, a su vez, a Pujol, 2005; Pauner, 2009; y Mora, 2010); en otros casos, como veremos, el (supuesto) informe se limita a manifestar que el impacto es 
nulo, sin aportar ningún dato o información que lo sustente ${ }^{8}$ (Senent, 2015 y 2018). Se trataría de claras manifestaciones de las múltiples «resistencias» que ha de combatir el mainstreaming, que mayoritariamente relegado a normativa de carácter no vinculante, o acompañado de «un claro desinterés a la hora de modificar los procesos y las rutinas políticas» ${ }^{9}$.

En el ámbito de la economía social son pocos los informes a los que hemos podido acceder y vendrían a corroborar las tendencias generales mencionadas. Así, por ejemplo, el Informe de impacto por razón de género (04/2013) que acompañó a la vigente Ley de cooperativas de la Comunidad Valenciana, después de afirmar que «no se aprecia la posibilidad de integrar objetivos de igualdad de oportunidades en el seno del proyecto, más allá de la utilización de un lenguaje no sexista («Identificación de los objetivos en materia de igualdad»); y que «no existen desigualdades de género previas en el ámbito de intervención de la norma, dado que la situación es de absoluta igualdad en derechos, oportunidades, limitaciones y requerimientos para hombres y mujeres» («descripción de la situación de partida»); se concluye valorando «el impacto de género como NULO, toda vez que no existen desigualdades de partida en relación a la igualdad de oportunidades y de trato entre mujeres y hombres en materia de cooperativas y no se prevé modificación alguna de esta situación». Tales afirmaciones contrastan, cuanto menos, con la previsión contenida en el artículo 42.6 del texto legal ${ }^{10}$, cuando afirma que "Las cooperativas procurarán incluir en su consejo rector un número de mujeres que permita alcanzar en su seno una presencia equilibrada de mujeres y hombres coherente con la composición de su masa social». Si el impacto se prevé nulo porque, además, se supone que «no existen desigualdades de partida», dicho mandato de procura carecería de sentido.

8 Como mínimo, «para valorar si los impactos de género serán positivos o negativos habrá que tener en cuenta si se promueve la autonomía de mujeres y hombres, esto es, la posibilidad de que mujeres y hombres decidan sobre sus propias vidas y si se promueve la igualdad de derecho y de hecho, es decir, la ausencia de discriminación directa o indirecta, así como de sus efectos», Emakunde y Ortiz , 2013:36.

9 «Probablemente para una parte del funcionariado encargado de redactar y supervisar la normativa, ésta se percibe como neutra al género y, en el mejor de los casos, como no discriminatoria, no siendo conscientes de que el trato igual a quien es desigual perpetúa o incrementa la desigualdad» (Alonso, Diz y Lois, 2010:131).

10 Decreto Legislativo 2/2015, de 15 de mayo, del Consell, por el que aprueba el texto refundido de la Ley de Cooperativas de la Comunitat Valenciana, https://www. boe.es/buscar/act.php?id=DOGV-r-2015-90416, 20/01/19, 17:39. 
Y lo mismo sucede en la MAIN (Memoria del análisis de impacto normativo) del Anteproyecto de Ley de sociedades laborales y participadas (05/2015) que, de forma aún más escueta, se limita a incluir un único párrafo, ya habitual en otros anteproyectos, que dice lo siguiente: "El anteproyecto de ley no afecta ni de manera positiva ni negativa a la igualdad de oportunidades entre mujeres y hombres, por lo que el impacto es nulo». No podemos detenernos en un análisis detallado de tal afirmación ${ }^{11}$; baste con apuntar que, sin embargo, la Ley ya en vigor incorpora en su artículo 13.3 el siguiente mandato: "La actuación de los administradores debe ser diligente, leal, responsable, transparente y adecuada a las peculiaridades de la sociedad laboral como modelo de sociedad específico. Deberán favorecer la generación de empleo estable y de calidad, la integración como socios de los trabajadores, la igualdad de oportunidades entre hombres y mujeres, y la conciliación de la vida personal, familiar y laboral.». Y sin embargo, a diferencia de lo que ya va sucediendo en algunos textos legales cooperativos, no se introduce ninguna norma explícita que siquiera promueva la presencia equilibrada en los órganos de representación y gobierno; ni tampoco se concreta medida alguna para, por ejemplo, favorecer la integración de las mujeres como socias, corregir los sesgos de género en el acceso a empleo a tiempo completo y correctamente remunerado, o facilitar la conciliación de socios y socias así como de personas trabajadoras por cuenta ajena ${ }^{12}$.

Por su parte, el Informe de evaluación de impacto de género del anteproyecto de Ley de microempresas cooperativas y cooperativas rurales de Castilla-La Mancha (02/2016), aunque realiza un esfuerzo de contextualización normativa, de "análisis de la situación actual de mujeres y hombres en el ámbito de actuación» y de «previsión de efectos

11 Puede verse un comentario extenso de un «informe» similar en nuestro trabajo de 2015 «En torno al informe de impacto de género sobre el anteproyecto de código mercantil de 2014».

12 No obstante, la buena noticia es que, como señala Amalia Rodríguez González en su comentario sobre "El órgano de administración de las sociedades laborales» (2018), se trata de "deberes que, aunque no están determinados en la norma, sí son, sin embargo determinables» y "deben ponerse en relación con el interés social». En relación con la presencia equilibrada en los órganos de administración, la autora considera que «la previsión del legislador en el caso de las laborales, es el establecimiento de un mandato, de un verdadero deber, a diferencia de lo que ocurre en las sociedades de capital, y por lo tanto en los casos de incumplimiento evidente del mismo, principalmente en el caso de grandes sociedades laborales, los administradores deberán responder siguiendo los presupuestos de responsabilidad de los administradores que se recogen en la LSC». 
sobre la igualdad de género y valoración del impacto», finaliza aseverando, en un único párrafo, que «desde la perspectiva de la igualdad de género, y en virtud de todo cuanto antecede, cabe decir, que si bien es cierto que el Anteproyecto de Ley de Microempresas Cooperativas y Cooperativas Rurales de Castilla-La Mancha no contiene ninguna medida ni actuación dirigida explícitamente a las mujeres, la cobertura legal contenida en el mismo podrá producir efectos sobre la igualdad de género, en tanto en cuanto contribuya a fomentar la creación de empleo estable para las mujeres a través de las microempresas cooperativas, y pueda mejorar la empleabilidad de las mismas en las zonas rurales, mediante las cooperativas rurales. De esta forma, el anteproyecto de ley podrá tener un impacto positivo en materia de igualdad de género en la medida en la que aumente la autonomía económica de las mujeres e incremente su empoderamiento, mejorando así su calidad de vida». Carece, pues, de los contenidos mínimos necesarios en un Informe de impacto de género.

En cuanto al Informe de evaluación del impacto de género del Anteproyecto de Ley por el que se modifica la Ley y el Reglamento de las sociedades cooperativas andaluzas (06/2016) también comienza por referir la normativa vigente en materia de igualdad entre mujeres y hombres; dedica varios párrafos a reproducir algunos datos suministrados por el Ministerio de Empleo y Seguridad Social respecto de las personas trabajadoras en situación de alta de la Seguridad Social en cooperativas y sociedades laborales ${ }^{13}$; a continuación afirma que "el anteproyecto de Ley [...] no producen [sic] en sí ningún desequilibrio ni afecta a la igualdad entre hombres y mujeres en ningún ámbito que se pudiere aplicar»; y concluye que "la disposición de referencia no genera efectos positivos ni negativos sobre la igualdad de oportunidades entre hombres y mujeres, por lo que no requiere mecanismo ni medida alguna para neutralizarlos».

Un informe diferente es el emitido (10/2015) por Emakunde-Instituto Vasco de la Mujer, relativo al Proyecto de Ley de Cooperativas presentado al Parlamento Vasco en 2016, con la finalidad de refundir e integrar varias modificaciones introducidas en la Ley 4/1993 de cooperativas de Euskadi14. Se trata de un Informe que Emakunde rea-

13 Puede reproducirse aquí nuestro comentario supra sobre los datos que publica trimestralmente el Ministerio de Empleo y Seguridad Social respecto a las personas dadas de alta en la Seguridad Social en cooperativas y sociedades laborales.

14 El proyecto de Ley, que fue presentado en el Parlamento Vasco el 3 de junio de 2016, figura en su sitio web en situación de "decaído». Con posterioridad, frente a un nuevo proyecto de Ley, Emakunde ha emitido un nuevo «Informe rela- 
lizó respecto de otro previo, del órgano promotor de la norma, y de su lectura puede deducirse claramente la diferencia sustancial que supone contar con conocimientos y práctica en la aplicación de la perspectiva de género. En él, el Instituto Vasco de la Mujer destaca, por una parte, la falta de aportación de datos, "ni cuantitativos ni cualitativos», relativos a la presencia de mujeres y hombres en el ámbito regulado; ni para sustentar la alegada previsión de que «la norma contribuirá a una disminución de las desigualdades, en la presencia de mujeres y hombres en los distintos órganos»; ni respecto de la previsión positiva sobre la eliminación o disminución de desigualdades en el acceso a los recursos. Por ello, se recomienda la aportación de diversos tipos de datos desagregados por sexo. Por otra parte, en base a diversos estudios que se citan, Emakunde concluye que «los datos indican claramente la existencia de una importante segregación vertical y horizontal en el sector»; y que "los ámbitos de decisión en las empresas de economía social de Euskadi se encuentran muy masculinizados». Se destaca sin embargo que, «en cuanto a la toma de decisiones, en la disposición adicional quinta, la norma prevé una presencia equilibrada de mujeres y hombres en los órganos de que disponga la cooperativa, al procurar como medida una presencia equilibrada de socios y socias» ${ }^{15}$.

tivo al Proyecto de Ley de Cooperativas de Euskadi, éste de 27 de marzo de 2018. Emakunde tiene competencia atribuida para la realización de dichos informes en el artículo 21 de la Ley 4/2005, de 18 de febrero, para la Igualdad de Mujeres y Hombres de Euskadi.

15 Por lo que respecta a «los objetivos y medidas planteadas en la futura norma para la superación o modificación de las normas sociales y valores de lo que se atribuye a las mujeres y a los hombres, en el Informe se señala que es propio de los valores y principios cooperativos favorecer la igualdad de género en la constitución y funcionamiento cooperativos». El análisis del texto lleva a también a advertir de que, aunque "el informe de impacto, apunta que en los artículos 145 y 146 del anteproyecto y art. 137 y 138 de la Ley 4/93 de cooperativas de Euskadi, en desarrollo de políticas de fomento del cooperativismo y para su implantación progresiva en la práctica, reforzará la base social femenina en las cooperativas, favorecerá su participación activa, informará de los derechos que las asisten como socias, etc.», sin embargo, "en el articulado del proyecto de Ley no se ha encontrado ninguna mención expresa al respecto». Otro aspecto que el Informe del órgano promotor alega pero que Emakunde no ha podido constatar es «la previsión de la adopción de otras medidas más allá del contenido del proyecto de norma, dirigidas a evaluar el género en las cuentas de la economía social, a promover actividades de formación y difusión de las políticas de igualdad y dar ayudas para emprender o acceder a la condición de socio, en que el género tiene una consideración específica». 
A la vista de todo ello, el Instituto Vasco de la Mujer efectúa varias recomendaciones ${ }^{16} 17$.

Consideramos se debe reclamar la realización correcta y efectiva de los Informes de Impacto de Genero de las normas reguladoras de las entidades de economía social; y ello no únicamente porque es obligatorio, sino porque aportan una verdadera utilidad, una "rentabilidad» social y también económica. En efecto, los informes sobre el impacto por razón de género de las normas reguladoras en general y de las de la economía en particular son una necesaria reflexión previa, tanto de la situación desigual de partida de mujeres y hombres como de las medidas que se pueden implementar para su erradicación. $Y$ desde un

16 - La incorporación explícita en el texto legal de «los principios generales que informan la constitución y funcionamiento de la sociedad cooperativa de Euskadi, constituyendo uno de estos principios «la igualdad de mujeres y hombres, con carácter transversal al resto de principios».

- La especificación en el artículo 20 de «las causas que supongan una discriminación arbitraria o ilícita a la hora de aceptar o denegar la admisión» de una persona socia, en la medida en que podrían entrar en contradicción o limitar el primer principio cooperativo.

- La inclusión en el art. 31 de un apartado donde diga que «las sociedades cooperativas promoverán la presencia equilibrada de socios y socias en todos los órganos colegiados que disponga»; y, de igual modo, en las organizaciones representativas de las cooperativas.

- La materialización del principio de igualdad de mujeres y hombres también en la regulación del Fondo de Reserva Obligatorio (art. 71), incluyendo «un apartado que recoja la formación y educación de las personas socias y trabajadoras en el fomento de una política efectiva de igualdad de género».

- El reconocimiento explícito (art. 145) de la especial promoción por parte de los poderes públicos de la Comunidad Autónoma del País Vasco de aquellas cooperativas «que desarrollen su labor con arreglo a principios de igualdad de mujeres y hombres y aquellas que establezcan mecanismos que aseguren efectivamente la presencia equilibrada de socios y socias en sus órganos de dirección».

- La "completa revisión y adecuación de los términos enunciados exclusivamente en masculino a lo largo de todo el texto del proyecto de Ley, tales como "socio», "socios», "promotor», «los gestores», "administradores», etc., de conformidad con la obligación de hacer un uso no sexista del lenguaje» (art. 18.4 Ley 4/2005, de 18 de febrero, para la Igualdad de Mujeres y Hombres de Euskadi)

17 Por su parte, el nuevo «Informe relativo al Proyecto de Ley de Cooperativas de Euskadi, de 27 de marzo de 2018, reitera de manera muy aproximada lo indicado en el anterior, de 26 de octubre de 2015, añadiendo algunas recomendaciones: hacer referencia expresa a la obligación que como el resto de empresas tienen las cooperativas «con más de 250 trabajadores» de elaborar y aplicar planes de igualdad; que en los estatutos o en el reglamento de régimen interno de las cooperativas incorporen medidas específicas para prevenir el acoso sexual y el acoso por razón de sexo en el trabajo; y que en el artículo 105 se incluya alguna recomendación para promover la inclusión en estatutos y RRI medidas para hacer efectivo el derecho de conciliación, así como para fomentar una mayor corresponsabilidad en la distribución de las cargas familiares. 
punto de vista de técnica jurídica se señala además un efecto ex post de los Informes: su carácter de "antecedente legislativo» que, según lo previsto en el artículo 3.1 del Código Civil español, es un elemento de la interpretación de la propia norma (Lousada, 2004:4618).

Y si éstas son utilidades predicables de la realización de (correctos) informes de impacto de género en cualesquiera normas jurídicas, cabe aún apuntar una específica de aquellas que regulen las entidades de economía social en general y las cooperativas en particular: los informes de impacto de género pueden ser una herramienta útil para valorar si cada norma reguladora de las entidades de economía social que se promulgue o modifique cumple el mandato de los principios y valores cooperativos y de la economía social en cuanto a la igualdad y no discriminación por razón de sexo (Senent, 2018).

\section{Expresar y desarrollar el mandato constitucional de la igualdad de trato y de oportunidades y de eliminación de discriminaciones y desigualdades}

Todas las leyes cooperativas del Estado español asumen de manera explícita que las cooperativas por ellas reguladas han de ajustarse a los principios cooperativos, por lo que el principio de igualdad y no discriminación por razón de sexo forma parte de su $" A D N »{ }^{19}$. Cabe decir que, en virtud de los mandatos constitucionales de los artículos 9.2 y 14 CE, tampoco podría ser de otra manera. No obstante, algunas leyes cooperativas españolas añaden algunos aspectos concretos en los que se ha de materializar la igualdad de mujeres y hombres en el ámbito empresarial ${ }^{20}$.

18 Ello no obstante, como también matiza el autor, dicho valor hermenéutico va a depender «1. de si el informe se sustenta en una correcta evaluación del impacto en función del género o si se ha realizado con ligereza, simplemente cubriendo un trámite formal a veces con el expediente de negar la existencia de impacto alguno, y 2 . de si, aún supuesta la corrección del informe, éste ha influido en el texto final de la norma, ya que, aunque se trata de un trámite preceptivo, el informe nunca se puede considerar vinculante».

19 En particular, la Ley de Sociedades Cooperativas Andaluzas (LSCA) que, al enunciar en su art. 4 los principios cooperativos, incluye en su apartado i) la «igualdad de género, con carácter transversal al resto de principios». La Ley de Cooperativas de Cantabria (LCCan) también considera «la igualdad de género» entre los «principios que la inspiran» (Preámbulo); y en el mismo sentido la Ley de Sociedades Cooperativas de Extremadura (LSCE).

20 Es el caso de la Ley de Cooperativas de Cataluña (LCCat), en su art. 10: "Las cooperativas deben garantizar la igualdad de trato y de oportunidades entre las mujeres y los hombres que forman parte de ellas»; y la Ley de Cooperativas de la Comuni- 
Una de las específicas manifestaciones del fomento legislativo de la adopción de medidas en pro de la igualdad y no discriminación de las mujeres en las cooperativas se produce cuando diversas normas, a la hora de regular su Fondo de Educación y Promoción Cooperativa (o reserva obligatoria equivalente) incluyen, como posible destino de sus recursos la realización de «acciones que fomentan la responsabilidad social empresarial, incluidas las de fomento de una igualdad de género efectiva» ${ }^{21}$. Otras veces, la legislación cooperativa remite las actuaciones en favor de la igualdad y no discriminación a su coordinación con las que lleven a efecto las Administraciones públicas correspondientes «en aplicación de sus programas contra las desigualdades de género»22.

Pero es la Ley de Cooperativas de Galicia la que, a nuestro entender, recoge de una manera más adecuada diversos aspectos en los que el funcionamiento de las cooperativas puede actuar en favor de la igualdad de mujeres y hombres. Es su Disposición adicional sexta ${ }^{23}$ la que, entre otros mandatos, establece que, «con el objetivo de la observancia y procura del principio de igualdad entre hombres y mujeres: 1. 'La Xunta de Galicia y las cooperativas fomentarán la erradicación en el ámbito de las sociedades cooperativas gallegas de la discriminación vertical y horizontal entre hombres y mujeres. 2. ${ }^{\circ}$ La Xunta de Galicia favorecerá el desarrollo de medidas que supongan ventajas concretas

dad de Madrid (LCCM) en su art. 105.4: "Serán aplicables a esas cooperativas y a sus socios trabajadores, con carácter inderogable [...] las disposiciones estatales sobre: [...] e) Permisos y excedencias por maternidad, paternidad, adopción de menores e igualdad de trato para la mujer».

21 LCCat, art. 85.1, f); en el mismo sentido, los arts. 68.2, LGC, apartados g), h) e i) («El Fondo de Formación y Promoción Cooperativa se destinará: [...] g) Para actuaciones para la conciliación de la vida personal, laboral y familiar. h) A actividades de fomento de la igualdad, en línea con lo previsto en la Ley 2/2007, de 28 de marzo, de trabajo en igualdad de las mujeres de Galicia. i) Para fomento de la responsabilidad social.»); 71.4, c) LSCA; y 84.4, c) LSCE.

22 Arts. 137.14 LSCRM, 135.14 LCCan, 111.8 LCCV y 198. 2 LCAs; en similar sentido, los arts. 115.4 y .5 LSCA; y 177.3, a) y .4 LSCE

${ }^{23}$ La Disposición adicional sexta, al igual que otras normas de la LCG, tiene su origen en la Disposición adicional tercera de la Ley $2 / 2007$, de 28 de marzo, de trabajo en igualdad de las mujeres de Galicia, que efectuaba un mandato a la Xunta de Galicia a fin de que remitiese al Parlamento un proyecto de ley de modificación de la Ley 5/1998, de 18 de diciembre, de cooperativas de Galicia, que, "además de adecuar la normativa actual a las nuevas necesidades que surgen en el ámbito del cooperativismo, integre el principio de igualdad y no discriminación por razón de sexo». La modificación había de ajustarse a unas bases que pueden considerarse, a nuestro entender, un elenco ejemplar de las medidas de que ha de dotarse una ley reguladora de cualquier tipo jurídico empresarial. 
y/o medidas de compensación de las desventajas sufridas por las mujeres en el ámbito laboral. 3. ${ }^{\circ}$ Las cooperativas procurarán contemplar en sus estatutos sociales medidas que se referirán al acceso a la condición de socia de trabajo, de socia trabajadora o incluso de asalariada, así como a su promoción profesional y demás aspectos de la situación y condiciones laborales de la persona afectada...».

Señala la norma varios de los principales aspectos a abordar en la actividad empresarial desde una perspectiva de género. Como es sabido, la discriminación o segregación vertical entre hombres y mujeres se refiere a las discriminaciones que padecen éstas últimas para acceder a puestos con poder de decisión ${ }^{24}$; y la horizontal, a «la dificultad de las mujeres para acceder a cargos generalmente estipulados como "masculinos" $\gg 25$. A las tareas para su erradicación pueden contribuir las denominadas medidas de acción positiva, cuyo fomento se encomienda a la Administración pública correspondiente (art. 11 LOIEMH). Además, se indica a las cooperativas la «necesidad de procurar» incluir en sus estatutos sociales medidas concretas relacionadas con aspectos especialmente sensibles de la posible discriminación de las mujeres: en las dificultades en el acceso a la condición de trabajadoras y de socias, en su promoción profesional y en las propias condiciones de prestación del trabajo (p. e., sesgos en los procesos de selección, falta de financiación para las aportaciones al capital, prejuicios que generan el denominado «techo de cristal», especiales dificultades en la formación y la conciliación...).

Por su parte, la más reciente Ley 9/2018, de 30 de octubre, de sociedades cooperativas de Extremadura, introduce un interesante artículo 64, dedicado a la configuración de un órgano denominado «comité de igualdad», cuya constitución será obligatoria para aquellas cooperativas «que cuenten con un número de socias y socios comunes igual o superior a 50», pudiendo adoptarlo las demás mediante acuerdo de su asamblea general. En tales casos, sus estatutos regularán el funcionamiento y la composición del comité, del que formará parte, con voz pero sin voto, un miembro del consejo rector; y en el que se tenderá a la paridad, teniendo "al menos, un número de integrantes mujeres proporcional al número de socios que tenga la sociedad cooperativa. Si no se alcanzase dicha proporcionalidad, en la memoria

$24 \mathrm{http}: / /$ www.surt.org/maletaintercultural/index.php?vlg=0\&vmd=0\&vtp=0\&vit=4\& tex $=18,20 / 01 / 19,19: 50$.

$25 \mathrm{http}: / /$ www.surt.org/maletaintercultural/index.php?vlg=0\&vmd=0\&vtp=0\&vit=4\& tex $=18,20 / 01 / 19,19: 50$. 
de las cuentas anuales de la sociedad cooperativa se deberá justificar, debidamente, el motivo y el procedimiento a seguir para alcanzarla» ${ }^{26}$.

Finalmente, cabe mencionar que la Proposición de Ley para garantizar la igualdad de trato y de oportunidades entre mujeres y hombres en el empleo y la ocupación, presentada por el Grupo Parlamentario Socialista el 07/09/18 y que actualmente se tramita en las Cortes Generales ${ }^{27}$ incluye propuestas expresas en relación con la legislación cooperativa 28 . Así, se propone:

a) que sean de aplicación a las personas socias trabajadoras y de trabajo de las cooperativas todas las medidas que se incluyen en la Ley dirigidas a las personas trabajadoras por cuenta ajena, con las correspondientes adaptaciones que sean necesarias para adecuarlas a su relación societaria;

b) que se incluyan en los estatutos sociales medidas dirigidas a garantizar la eliminación de obstáculos al acceso igualitario a la condición de socia de trabajo, de socia trabajadora o de asala-

26 Entre sus funciones, que se establecerán estatutariamente, estarán al menos las siguientes:

«a) Impulsar la participación e integración de las socias en todos los órganos sociales.

b) Proponer el establecimiento de medidas de conciliación de la vida laboral, familiar y personal, tales como por ejemplo la ordenación del tiempo de trabajo, flexibilidad laboral, incentivar a los hombres a que hagan uso de las posibilidades de flexibilizar la jornada laboral, establecer el calendario laboral en función del calendario escolar, dar preferencia en los turnos de trabajo a quienes tienen responsabilidades familiares, formación en horas de trabajo y en la propia sociedad cooperativa, no primar las horas de presencia en el trabajo sino los logros obtenidos.

c) Proponer la fijación de sanciones específicas relacionadas con el acoso sexual y por razón de sexo.

d) Definir un protocolo de actuación para casos de acoso.

e) Proponer la revisión de las denominaciones de los puestos de trabajo para eliminar connotaciones que hagan referencia a uno u otro sexo.

f) Promover un ambiente y condiciones de trabajo basado en valores como el respeto mutuo, igualdad y valoración de la diversidad.

g) Proponer la impartición de cursos de formación en igualdad para socias y socios de la cooperativa.

h) Promocionar e incentivar la asistencia y participación de las mujeres a las asambleas».

$27 \mathrm{http}: / /$ www.congreso.es/public_oficiales/L12/CONG/BOCG/B/BOCG-12-B-306-1. PDF, 21/01/19, 8:25.

28 En cambio, la Proposición de Ley integral de igualdad y transparencia retributiva entre mujeres y hombres presentada por el Grupo Parlamentario Popular en el Congreso el 19/10/18, no contiene ninguna propuesta específica en relación con las cooperativas. 
riada; la erradicación de la discriminación vertical y horizontal; y la promoción profesional y societaria de las mujeres;

c) que al menos el $20 \%$ de la dotación al Fondo obligatorio destinado a actividades de formación y promoción cooperativa se aplique a actividades de fomento de la igualdad efectiva de mujeres y hombres 29 ;

d) que se procure la presencia equilibrada de mujeres y hombres en los órganos sociales, obligatorios o voluntarios, y en su estructura empresarial; en las entidades representativas del movimiento cooperativo, y en los órganos administrativos de promoción y difusión del cooperativismo;

e) que las actuaciones de promoción del cooperativismo por parte de las Administraciones Públicas, en especial las relativas al empleo, incluyan medidas para la remoción de las desigualdades de género; en especial, aquellas que incorporen medidas para conciliación de la vida societaria, laboral y familiar, o que establezcan mecanismos que aseguren efectivamente la presencia equilibrada;

f) que las cooperativas estén obligadas a proporcionar a la administración competente, anualmente, datos estadísticos desagregados; y que su incumplimiento sea sancionado como infracción administrativa.

\section{Promover la presencia equilibrada}

La LOIEMH indica, en su Disposición Adicional Primera, que «se entenderá por composición equilibrada la presencia de mujeres y hombres de forma que, en el conjunto a que se refiera, las personas de cada sexo no superen el sesenta por ciento ni sean menos del cuarenta por ciento». Y su artículo 75 (que forma parte del Título VII de la Ley, "La igualdad en la responsabilidad social de las empresas»), titulado «Par-

29 Una enmienda del Grupo parlamentario Popular (núm. 243) propone que la dotación al Fondo obligatorio se aplique a actividades «específicas» de fomento de la igualdad efectiva de mujeres y hombres; y que no se establezca el mínimo del $20 \%$ de la dotación, sino que sea "proporcional a variables como el número de cooperativistas». Dicha formulación dejaría un amplio margen de discreccionalidad a las cooperativas, que, paradójicamente, podrían tomar en consideración variables que tengan efectos agravantes de las desigualdades: tal sería el caso, por ejemplo, de que la variable a considerar fuese el porcentaje de mujeres socias en sectores masculinizados; o que podrían llegar a justificar su no aplicación o una aplicación mínima en cooperativas con pocas (o, al contrario, muchas) personas socias. 
ticipación de las mujeres en los Consejos de administración de las sociedades mercantiles», establece que "las sociedades obligadas a presentar cuenta de pérdidas y ganancias no abreviada procurarán incluir en su Consejo de administración un número de mujeres que permita alcanzar una presencia equilibrada de mujeres y hombres en un plazo de ocho años a partir de la entrada en vigor de esta Ley» ${ }^{30}$. Como veremos, la legislación cooperativa ha incluido, hasta la fecha, varias normas que tienden a parecerse a lo previsto en el citado artículo, en relación con el fomento de la presencia de mujeres en sus principales órganos de administración; no obstante, la necesidad de equilibrar el acceso de las mujeres a la actividad económica y societaria de las empresas de economía social es mucho más amplia.

\subsection{Eliminar barreras al acceso a la condición de socia y a la participación en igualdad en la actividad cooperativizada. La titularidad compartida}

Un primer nivel de dificultades, a veces poco visibles, con que suelen encontrarse las mujeres en su relación con las entidades de la Economía social se sitúa en el mismo acceso a la cualidad de socia y/o asalariada. Como hemos indicado reiteradamente (Senent, 2011:61), diversos estudios coinciden en que si bien la presencia de mujeres en las cooperativas es superior a la que se da en en el mercado laboral general, son un porcentaje significativamente menor las que lo están en cualidad de socias. Habiendo quedado patente que su nivel formativo es igual o superior a la de los hombres, no nos cabe duda de que tales obstáculos traen causa, directa o indirecta, de los estereotipos de género, tanto de carácter general como algunos específicos, como la falta de titularidad oficial de los bienes que, en su caso, se requieran (así, en las cooperativas agrarias, la titularidad de la tierra; en las cooperativas de servicios empresariales, la titularidad de la actividad económica co-

30 Otros artículos de la LOIEMH relacionados con la presencia equilibrada en el ámbito empresarial son el 30 (sobre el que tratamos infra, en relación con la titularidad compartida de las explotaciones agrarias); el 54 (la Administración General del Estado y sus organismos públicos vinculados o dependientes «observarán el principio de presencia equilibrada en los nombramientos que le corresponda efectuar en los consejos de administración de las empresas en cuyo capital participe»); y el 50 (al regular el «Distintivo para las empresas en materia de igualdad», establece en su apartado 4 que "para la concesión de este distintivo se tendrán en cuenta, entre otros criterios, la presencia equilibrada de mujeres y hombres en los órganos de dirección y en los distintos grupos y categorías profesionales de la empresa...»). 
rrespondiente), o la mayor dificultad en el acceso a la financión de sus iniciativas ${ }^{31}$.

Es en ese sentido que, como hemos visto, la LCG establece en su Disposición adicional sexta, entre otros mandatos, que, «con el objetivo de la observancia y procura del principio de igualdad entre hombres y mujeres: [...] 2. ${ }^{\circ}$ La Xunta de Galicia favorecerá el desarrollo de medidas que supongan ventajas concretas y/ o medidas de compensación de las desventajas sufridas por las mujeres en el ámbito laboral»; y «3. ${ }^{\circ}$ Las cooperativas procurarán contemplar en sus estatutos sociales medidas que se referirán al acceso a la condición de socia de trabajo, de socia trabajadora o incluso de asalariada, así como a su promoción profesional y demás aspectos de la situación y condiciones laborales de la persona afectada...». Tales medidas, que las cooperativas pueden implementar y desarrollar en su normativa o en sus planes internos, podrán ir desde una vigilancia específica para la eliminación de sesgos sexistas en los procesos de selección de personas trabajadoras y socias hasta la elaboración y aplicación de completos planes de igualdad (sea o no obligatoria su adopción por cada entidad).

Una de las dificultades en el acceso a la condición de socia podría paliarse mediante el fomento de la aplicación efectiva de la Ley 35/2011, de 4 de octubre, sobre titularidad compartida de las explotaciones agrarias (LTCEA). Porque, en efecto, como ha recordado María Eugenia Pérez, presidenta del Comité de Igualdad de Género de la Alianza Cooperativa Internacional en su Declaración del Día Internacional de las Mujeres de 2018, «no podemos olvidar la existencia de muchas mujeres "invisibles" en áreas rurales, vinculadas a granjas agrícolas y ganaderas sin tener una relación legal o administrativa con ellas, y para las cuales su trabajo en las explotaciones agrícolas se considera "apoyar a su familia" ${ }^{32}$. Se da en ellas «la doble marginación por ser mujer y por vivir en una zona rural» (Esteban, Gargallo y Pérez, 2018:119 y 120).

Frente a ello, en España, el artículo 30 LOIEMH dirige un mandato a los Ministerios de Agricultura y de Trabajo para que desarrollen la figura jurídica de la titularidad compartida en el sector agrario; y para el

31 Sobre la constatada «discriminación financiera» que padecen las mujeres, ver, p. e., Nuria MOLINA, infoautonomos.eleconomista.es, 201/04/18, «Mujeres emprendedoras: cuando la financiación no llega», https://infoautonomos.eleconomista.es/blog/ mujeres-emprendedoras-financiacion-no-llega/ , 22/01/19, 12:09.

32 https://ica.coop/en/media/library/declaration/declaration-internationalcooperative-alliance-international-womens-day?_ga=2.147496887.1039583731.15480 77192-1601830634.1547739350, 21/01/19, 14:49. 
desarrollo de «acciones dirigidas a mejorar el nivel educativo y de formación de las mujeres, y especialmente las que favorezcan su incorporación al mercado de trabajo y a los órganos de dirección de empresas y asociaciones». En nuestra opinión, la figura jurídica de la titularidad compartida puede y debe entenderse no sólo como una forma de corregir la actual invisibilidad de la participación de las mujeres en la actividad empresarial ${ }^{33}$ sino también como una manifestación más de la tendencia hacia su presencia equilibrada. Por lo demás, el apartado 1 del artículo 30 LOI hace referencia únicamente a su desarrollo en el sector agrario, pero no encontramos razones para tal limitación, antes al contrario, consideramos que sería oportuno explorar su extensión a otros sectores productivos y comerciales ${ }^{34}$.

En relación con el necesario fomento de su aplicación efectiva, la ya citada Proposición de Ley para garantizar la igualdad de trato y de oportunidades entre mujeres y hombres en el empleo y la ocupación (Grupo Parlamentario Socialista, 07/09/18) incluye algunas propuestas específicas ${ }^{35}$. En cualquier caso, como hemos argumentado con anterioridad (2012) el reconocimiento y la visibilización del trabajo de las mujeres que puede suponer su acceso a la titularidad compartida puede ser también una vía para su incorporación efectiva a la participación y gestión de las empresas de economía social, sea en el ámbito rural o en el urbano.

33 «Actualmente el 30 por ciento de la población femenina de España vive en zonas rurales, ascendiendo a un 82 por ciento el total de las mujeres que en calidad de cónyuges o hijas trabajan en el campo. Sin embargo, en la mayoría de los casos, el 71,2 por ciento concretamente, los titulares de la explotación son hombres», RED FEMINISTA, 2009:2.

34 Para un estudio más detallado sobre la figura de la titularidad compartida de las explotaciones agrarias ver nuestro trabajo «La Ley de titularidad compartida de las explotaciones agrarias y sus potenciales efectos jurídicos en las entidades de economía social».

$35 \mathrm{El}$ art. 41 de la Proposición, titulado "Garantías para la efectividad de la titularidad compartida de las explotaciones agrarias. Extensión a otras empresas» indica que:

«1. Las Administraciones Públicas con competencia en agricultura, pesca, alimentación y medio ambiente dotarán de recursos presupuestarios la ejecución de programas anuales y plurianuales dirigidos a la aplicación efectiva de la Ley 35/2011, de 4 de octubre, sobre titularidad compartida de las explotaciones agrarias.

En particular, se fomentará la formación, el asesoramiento y la ayuda económica a las mujeres agricultoras que manifiesten su interés en acceder a las diferentes modalidades de reconocimiento de su actividad.

2. Las Administraciones Públicas promoverán la extensión de la figura de la titularidad compartida a microempresas, pequeñas y medianas empresas de sectores diferentes al agrario». 
Otro aspecto a tener en consideración en el proceso de incorporación de las mujeres a las entidades de economía social es el de la llamada segregación horizontal que, como se ha indicado ya, también se da en este ámbito. No es tarea fácil, sin embargo, debido a que sus causas, directas o indirectas, son estereotipos de género «normalizados» socialmente. Es por ello que, acertadamente, en la LCG se establece, en su Disposición adicional sexta un mandato explícito para que la principal administración pública en su ámbito, la Xunta de Galicia, intervenga junto con las cooperativas para fomentar su erradicación. También aquí pueden y deberían implementarse un amplio abanico de medidas, comenzando por intervenciones al respecto en todos los niveles educativos, y acabando en la actividad concreta de cada cooperativa, que puede trabajar por la incorporación de mujeres a sectores y actividades «masculinizados» y de hombres a los «feminizados».

Sea como sea, en la adopción de estas y otras medidas, tendentes también a superar otras barreras, como las que dificultan la presencia y participación equilibrada de mujeres y hombres en la estructura técnica, de gestión de la cooperativa; o en los procesos de promoción interna; y en las políticas y actividades de formación de las empresas de economía social, dos aspectos son especialmente importantes. Uno, la atención al favorecimiento de la conciliación y corresponsabilidad de las personas socias y trabajadoras, que permitirá su participación en igualdad, y sobre la que volvemos luego; y otro, la necesaria implementación de líneas de apoyo, económico y experto, por parte de las administraciones públicas correspondientes.

Finalmente, una barrera, quizá más sutil, con que se encuentran las mujeres en su relación con las cooperativas y otras entidades de la economía social es la falta de equiparación en el tratamiento jurídico de las figuras de «cónyuge» y la denominada en algunos textos legales como «persona con análoga relación de actividad»; en otros casos se prefiere la más amplia denominación de "quien conviva con la persona socia». En relación con ello se constata que los cambios sociales en la organización de la convivencia privada y en las relaciones de afectividad han ido introduciendo, tanto en la regulación de las sociedades de capital como en la legislación cooperativa, menciones que tienden a equiparar con la persona cónyuge de la socia a su «pareja de hecho» y/o a otras personas que con ella conviven o con la que mantienen «relaciones de afectividad».

Tales comparaciones, no siempre equivalentes ni suficientemente determinadas, se hacen en la normativa cooperativa en relación, fundamentalmente, con tres aspectos: a) la posibilidad de ejercicio del 
voto en representación de la persona socia ${ }^{36} ;$ b) la transmisibilidad en su favor de aportaciones al capital ${ }^{37} \mathrm{u}$ otros bienes $\operatorname{cooperativos}^{38}$ de la persona socia; y c) en materia de incompatibilidades ${ }^{39}$ y conflictos de interés con la cooperativa ${ }^{40}$. Otras veces, se hace una extensión general de los derechos de |@s cónyuges de las personas socias ${ }^{41}$. Y manifestaciones específicas de la extensión de derechos se dan también en la regulación de las personas beneficiarias de los bienes y servicios que suministran las cooperativas de consumo ${ }^{42}$ y de viviendas ${ }^{43}$, que muchas veces (no siempre) incluyen tanto a las propias personas socias como a quienes «con ellas convivan».

En cualquier caso, la variabilidad y escasa definición actual de los límites de las figuras a las que se equipara en derechos nos lleva a concluir que sería deseable armonizar el tratamiento de dicha equiparación entre cónyuge y «persona con análoga relación de afectividad»; o que quizá sea preferible buscar algún tratamiento más inclusivo, dada la creciente variedad en la organización de la convivencia privada y en las relaciones de afectividad ${ }^{44}$.

\subsection{Fomentar las políticas de conciliación/corresponsabilidad}

La necesidad de conciliar la vida laboral y societaria con la familiar y personal ha sido identificada como uno de los principales obstáculos con que se enfrentan las mujeres en sus esfuerzos por alcanzar la igualdad de trato en todos los ámbitos. Además, con el desarrollo de nuevos modelos de masculinidad no patriarcales se ha puesto de manifiesto la necesidad de reivindicar dicha conciliación también para los hombres,

36 Arts. 49.1 LCCat; 126 LSCE; 43 LCIB; 52 LCAs; 50 LCC-LM; 33.2 LCAr; $37.3 \mathrm{LCCV}$. El artículo 33.2 LCAr reconoce esta posibilidad de representación en las cooperativas de consumidores y usuarios, en las de viviendas y en las agrarias.

37 Arts. 54 LSCE; 169 LCAs; 81.3, a) y 133.6 LCC-LM.

38 Art. 125.7 LCCat.

39 Arts. 40, 44.2 y 47 LSCE; 59 LSCRM; 61 LCIB; 77.4 LCAs; 57 y 138. 4 LCC-LM; 48, c) LSCA.

40 Arts. 41 LSCE; 66 LCIB; 52.1 LSCA.

41 Disp. ad. 3. ${ }^{\text {a }}$ LCCM; Disp. ad. 3. ${ }^{a}$ LCLR

42 Arts. 88.1 LCoop; 123.1 LCCCyL; 111.1 LSCRM; 105. 1 LCE; 110 LCIB; 152. 1 LCAs; 96 LSCA; 119.1 LCCan; 82.1 LCAr; 90.1 LCCV; 68.2 LFCN. El artículo 80.1 LCAr reconoce también esta posibilidad en las cooperativas agrarias.

43 Arts. 89.1 LCoop; 117.1 LCCCyL; art. 112.1 LSCRM; 113.1 LCCan; $91.1 \mathrm{y}$ 2 LCCV.

44 Para un mayor desarrollo, ver SENENT VIDAL, M. ${ }^{a}$ José (2015), «En torno al Informe de impacto de género...», op. cit. 
no sólo como eficaz colaboración con la lucha de las mujeres sino además como derecho a disfrutar de las tareas de cuidados de gente mayor y pequeña, que tradicional y culturalmente les han sido escamoteados. Es por ello que los denominados derechos de conciliación han ido accediendo tanto a la legislación laboral como a la de las entidades de la economía social, llegando a formularse por la doctrina la necesidad de su consideración explícita como derechos constitucionales; y que, consecuentemente, sea más correcto hablar de corresponsabilidad.

El reconocimiento de los derechos de conciliación/corresponsabilidad en las cooperativas puede considerarse implícito en varios de sus Principios. La relación más evidente se hace con el Primer principio que, como es sabido, expresa un mandato de erradicación de toda discriminación, también por razón de sexo, lo que ha llevado a la Alianza Cooperativa Internacional a establecer que «las cooperativas deberían asegurar, mediante acciones positivas, que no existen barreras para ser socio por razón de sexo. Además, las cooperativas deberían asegurar que las mujeres participan en igualdad numérica en sus programas de educación y desarrollo de liderazgo» (International Cooperative Alliance, 1995:47). Pero también pueden identificarse conexiones con otros Principios cooperativos. En particular, consideramos que la aplicación de la perspectiva de género al Principio Cuarto, "autonomía e independencia» y al Séptimo, «Interés por la comunidad» conducen a la necesidad de fomentar la conciliación de las personas socias y trabajadoras de las cooperativas. Así, fortalecer la autonomía e independencia de las cooperativas debe significar también el fortalecimiento de las de sus personas socias, especialmente de las de las mujeres, y para ello se ha de fomentar su independencia económica y su conciliación. Y si «las cooperativas trabajan para conseguir el desarrollo sostenible de sus comunidades mediante políticas aprobadas por sus socios», "el concepto de «comunidad» debe alcanzar al entorno más próximo de las mujeres cooperativistas, a sus familiares y a sus espacios domésticos (conciliación)» (Senent, 2011:69-71).

En el Estado español, la legislación cooperativa y de la economía social ha ido incluyendo menciones explícitas a los derechos de conciliación. Así, por ejemplo, la Ley de sociedades cooperativas andaluza (art. 4, f) y la Ley de cooperativas de Cantabria (Preámbulo), integran la conciliación entre sus principios informadores; el Texto refundido de la Ley de cooperativas de Aragón (art. 59.4) y la Ley de cooperativas de Galicia (art. 68.2, g), la consideran objeto de financiación por los recursos del fondo de educación y promoción cooperativa; ésta última, además (art. 43.4) ordena que, en aras de procurar la representación equilibrada de mujeres y hombres en su consejo rector, se posibilite «entre los miembros de este órgano la compatibilidad y conciliación de su 
ejercicio profesional pleno con las situaciones de maternidad y paternidad y los cuidados de menores y personas dependientes». También demanda la Ley de cooperativas de Galicia (art. 107.1), en el ámbito concreto de las cooperativas de trabajo asociado, que «El régimen de prestación de trabajo posibilitará entre las personas socias de la cooperativa la compatibilidad y conciliación de su ejercicio profesional pleno con las situaciones de maternidad y paternidad y los cuidados de menores y personas dependientes».

En el ámbito estatal, la Ley de Economía social (art. 4) incluye la conciliación de la vida personal, familiar y laboral entre los principios orientadores de todas sus entidades (art. 5). Por su parte, la reciente Ley de sociedades laborales y participadas reclama de sus personas administradoras una actuación que favorezca, entre otros aspectos, "la conciliación de la vida personal, familiar y laboral» (art. 13), que también se incluye entre los principios informadores de las participadas (arts. 18 y 19). Por lo demás, es cada vez más habitual encontrar en los textos de lo que ha venido en denominarse softlaw (memorias de sostenibilidad, planes de igualdad...), medidas que, con mayor o menor profundidad, detalle y efectividad, procuran la conciliación en cooperativas y otras entidades de la Economía social, muy especialmente en el contexto de la denominada Responsabilidad social corporativa.

Sin embargo, un problema específico con que se encuentran en algunos casos las personas socias de cooperativas de trabajo asociado a la hora de reclamar la aplicación de los derechos de conciliación radica en la naturaleza de su relación con la cooperativa, societaria y no laboral por cuenta ajena. La complejidad y detalle de la cuestión excede de la extensión de este trabajo, por lo que remitimos a nuestro análisis al respecto en Senent y García, 2016. En síntesis, nuestra posición es la siguiente: dado que no hay una mención explícita en la Constitución española a los derechos de conciliación, no pueden beneficiarse de una tutela erga omnes; por ello, mientras que en el ámbito laboral encontrarían protección mediante la aplicación de lo previsto en su legislación ${ }^{45}$, en el ámbito societario cabría un amplio margen de dispo-

45 Cfr. el art. 4 del Real Decreto Legislativo 2/2015, de 23 de octubre, por el que se aprueba el texto refundido de la Ley del Estatuto de los Trabajadores, que no enuncia entre los derechos laborales básicos el de conciliación, y 34.8, que sí lo reconoce expresamente. En el empleo público, el art. 14, j) del Real Decreto Legislativo 5/2015, de 30 de octubre, por el que se aprueba el texto refundido de la Ley del Estatuto Básico del Empleado Público, reconoce el derecho individual de los empleados públicos «a la adopción de medidas que favorezcan la conciliación de la vida personal, familiar y laboral», que se desarrolla de modo particular en su art. 49, dedicado a los permisos por motivos de conciliación, entre otros. 
nibilidad de acuerdo con la legislación vigente en materia cooperativa. Ésta, para su concreción suele remitir a la regulación interna (estatutos sociales, reglamento de régimen interno, acuerdos de la asamblea general...).

Ello no obstante, sostenemos la plena aplicabilidad de la normativa, española y europea, en materia de conciliación también a las personas socias de las cooperativas de trabajo asociado. El motivo «no radica tanto en el carácter de su relación (societaria) con la cooperativa sino en la naturaleza de su prestación efectiva: «su esfuerzo personal y directo, a tiempo parcial o completo, a través de la organización en común de la producción de bienes o servicios para terceros» (art. 80.1, LC). Dicho de otro modo: la coincidencia entre el trabajo de la persona socia cooperativa y de la trabajadora asalariada no radica en la relación de la que trae causa la prestación del trabajo, societaria en el primer caso, laboral en el segundo, sino en el contenido de tal prestación. [...] Dicho aún de otro modo, sea la causa del contrato laboral o societaria, da lugar a una prestación de trabajo. Si el trabajo es coincidente en ambos supuestos, consideramos que también deberá serlo la normativa [...] aplicable en materia de derechos de conciliación, sobre todo si se tiene en cuenta que su finalidad es precisamente conciliar vida profesional y vida familiar en sus distintas manifestaciones». La conciliación formaría así parte de un conjunto de materias "paralaboralizadas» debido a la concurrencia de razones de "orden público profesional, mínimo, indisponible y protegido por el Estado, con el que se pretende tutelar a la fuerza de trabajo y evitar unos niveles de explotación socialmente inaceptables» (López Mora, 1999:17). Tal parece ser también el sentido del art. 139.1 LCEx al atribuir un carácter de norma de aplicación directa, a «los derechos reconocidos en la legislación laboral que» afecten al principio de igualdad.

Por lo demás, todo el trabajo interpretativo sería innecesario si, como es justo, hubiese un reconocimiento constitucional expreso de la naturaleza de derechos fundamentales de los derechos de conciliación. En tal caso, la construcción sería justamente la contraria: la legislación habría de aplicarlos y regularlos, teniendo siempre como límite su contenido esencial; no podrían ser ignorados o disponer sobre tal contenido esencial. Mientras tanto, resulta altamente recomendable para la efectividad de los derechos de las personas socias de las cooperativas, proceder a una regulación interna explícita, ya sea en los estatutos sociales o en los reglamentos de régimen interno, ya en las memorias de sostenibilidad, en los planes de igualdad, en los acuerdos sobre responsabilidad social cooperativa..., etc. 


\subsection{Alcanzar la presencia equilibrada en los órganos de gobierno y representación}

Son todavía relativamente pocos los estudios sobre la contradicción que supone entre teoría y práctica de las entidades de economía social la «baja participación de las mujeres en puestos de poder, tanto en puestos ejecutivos como en puestos de gobierno» (Elio, 201646), pero todos coinciden en constatar dicha situación [Carretero y Avello, 2011; Elio, 2006, 2007 y 2016; Esteban, Gargallo y Pérez, 2011; Hernández, Ruiz, García y Pedrosa, 2018; Mateos, Iturriuz, y Gimeno, 2007; Meliá, Carnicer y Juliá, 2017:25347; Palomo, García, Gutiérrez, y Fernández, 201348; y VV. AA. (coord. Meliá, Carnicer y Juliá, 2017)].

Ya hemos avanzado la definición de composición equilibrada que hace la LOIEMH: "la presencia de mujeres y hombres de forma que, en el conjunto a que se refiera, las personas de cada sexo no superen el sesenta por ciento ni sean menos del cuarenta por ciento» (Disp. Ad. 1. ${ }^{a}$ LOI); y que su más conocida aplicación en el ámbito económico privado es la previsión del art. 75 LOIEMH. Pero además, la LOIEMH contiene otras normas que promueven la presencia de las mujeres en la actividad empresarial; así, por ejemplo, el también citado artículo 30

46 Ver, para el ámbito concreto de las cooperativas y especialmente las vascas y las del Grupo cooperativo Mondragón, los diversos trabajos al respecto de Eunate ELIO CEMBORAIN.

47 «Los resultados de este estudio constatan que tan solo un $26 \%$ de las cooperativas agroalimentarias más grandes de España (con un volumen de facturación mayor a los 10 millones de euros) cuentan con alguna mujer en su Consejo Rector, siendo la media de 1,5 mujeres en los Consejos, dato reducido teniendo en cuenta que el tamaño medio de los mismos es de 10,8 miembros [Meliá et al. (2016)]. Esta proporción, sin embargo, es mayor en los equipos directivos de esas entidades (un 59\% de las cooperativas cuentan con alguna mujer directiva), aunque coincidiendo con Cabrerizo (1999), Langreo y Benito (2006), Ryan y Haslam (2005; 2007) y Cooperativas Agro-alimentarias de España (2011), la presencia femenina disminuye conforme aumenta el nivel de responsabilidad, siendo una excepción las mujeres que ejercen el rol de directoras generales; confirmándose la teoría del «techo de cristal». Por último, hemos constatado que la presencia femenina en los equipos directivos aumenta con el tamaño de la cooperativa, coincidiendo con los resultados obtenidos por Esteban et al. (2015)», Meliá, Carnicer y Juliá, 2017:253.

48 «la presencia de mujeres en el sector de las cooperativas de crédito que se ha estudiado no resulta especialmente destacada; si bien, en el último año analizado, 2011, con un $11,40 \%$, se sitúa en valores intermedios en relación con los estudios previos para los diversos países europeos [...] permite avanzar también que, a dicho ritmo, sería preciso alcanzar el año 2045 para que, mediante la confirmación de la tendencia analizada, se alcanzase la proporción del $40 \%$ planteada por la propuesta de normativa europea. Según esto parece aún lejano el momento de superar el denominado techo de cristal», Palomo, García, Gutiérrez, y Fernández, 2013:10. 
LOIEMH, para el desarrollo de la titularidad compartida de las explotaciones agrarias y de acciones que favorezcan la incorporación de mujeres a los órganos de dirección de empresas y asociaciones del ámbito rural.

La promoción de la participación de las mujeres en el gobierno de las cooperativas está fundamentada en el Segundo principio cooperativo, "gestión democrática por parte de los socios», que indica que «las cooperativas son organizaciones gestionadas democráticamente por los socios, los cuales participan activamente en la fijación de sus políticas y en la toma de decisiones. Los hombres y mujeres elegidos para representar y gestionar las cooperativas son responsables ante los socios...». La Declaración de Manchester de la Alianza Cooperativa Internacional también manifiesta que "gran parte del futuro éxito del movimiento cooperativo dependerá de la voluntad de reconocer una verdadera igualdad entre las mujeres y los hombres en las deliberaciones de las organizaciones cooperativas» (International Cooperative Alliance, 1996:107). Y más adelante, al analizar los retos de futuro, afirma que «al afrontar estos desafíos, las cooperativas se beneficiarán si se aseguran de que las puertas están abiertas a las mujeres en cuanto socios, líderes elegidos, empleados y directivos. El hacerlo será un buen negocio a causa del poder económico que representan las mujeres, aunque son propietarias de menos de lo que por su número y trabajo merecen. De forma más fundamental e importante, el hacerlo es simple justicia, en armonía con los compromisos básicos evidentes en los círculos cooperativos desde sus comienzos» (International Cooperative Alliance, 1996:131).

La legislación cooperativa española ha incluido, hasta la fecha, varias normas relativas a la presencia equilibrada. Así lo hace la Ley de Cooperativas de la Comunidad Valenciana que, en su modificación de 2015, incorpora un nuevo punto 6 a su artículo 42, con el siguiente texto: «6. Las cooperativas procurarán incluir en su consejo rector un número de mujeres que permita alcanzar en su seno una presencia equilibrada de mujeres y hombres coherente con la composición de su masa social». Por su parte, la Ley de Sociedades Cooperativas Andaluzas (art. 38.4) y la Ley de Cooperativas de Galicia (art. 43.4) establecen que «Las sociedades cooperativas procurarán la presencia equilibrada de socios y socias en el consejo rector ${ }^{49}$; el texto gallego añade que «A tal objeto, se posibilitará entre los miembros de este órgano la com-

49 La LCG también demanda la procura de presencia equilibrada de mujeres y hombres en la composición y organización del Consejo Gallego de Cooperativas, así como las de sus órganos (art. 136.4). 
patibilidad y conciliación de su ejercicio profesional pleno con las situaciones de maternidad y paternidad y los cuidados de menores y personas dependientes». Por su parte, la Ley de Cooperativas de Cataluña indica, en su artículo 10, «Medidas de igualdad», que «las cooperativas deben garantizar la igualdad de trato y de oportunidades entre las mujeres y los hombres que forman parte de ellas, y tender a representar a los dos sexos de forma proporcional a su presencia en los cargos de la cooperativa». La más reciente Ley de sociedades cooperativas de Extremadura incluye en su art. 50.7 que «La sociedad cooperativa asegurará la representatividad de todos sus socios y socias. Para ello, el consejo rector, en su composición, tenderá a la paridad y habrá, al menos, un número de integrantes mujeres proporcional al número de socias que tenga la sociedad cooperativa. El incumplimiento de esta obligación conllevará la prohibición a la sociedad cooperativa de obtener la condición de beneficiaria de las subvenciones cuyas bases reguladoras y convocatorias sean aprobadas por la Administración de la Comunidad Autónoma de Extremadura. Si no se alcanzase la paridad, en la memoria de cuentas anuales de la sociedad cooperativa se deberá justificar, debidamente, el motivo y el procedimiento a seguir para alcanzarla. Además, el incumplimiento de la proporcionalidad respecto al número de socias que tenga la cooperativa supondrá la comisión de una infracción leve de las tipificadas en el artículo 185.3 de esta Ley» ${ }^{50}$.

El resto de leyes de cooperativas del Estado español no contienen alguna norma similar. No obstante, cabe interpretar que el art. 75 LOI es plenamente aplicable a las cooperativas que, estando "obligadas a presentar cuenta de pérdidas y ganancias no abreviada» procedan a nombrar cargos de su órgano general de administración (ver al respecto, Senent, 2012). Por lo demás, tanto la Ley estatal (art. 33, párs. segundo y tercero de la LC) como diversas Leyes autonómicas de cooperativas (véase, p. e., los arts. 45.4 LCE; 41.3 LCCat; 42.5 LCCV) recogen la posibilidad de que los estatutos sociales establezcan cuotas de representación en el órgano de administración en favor de determinados colectivos. No parece que hayan razones objetivas para impedirlo cuando se trate de alcanzar la «presencia equilibrada» de mujeres y hombres. Para ello, las normas de autoorganización de la cooperativa

50 La LSCE, a semejanza de la LCG, indica que en la composición del Consejo Superior del Cooperativismo de Extremadura «se garantizará la representación equilibrada de hombres y mujeres», en los términos establecidos para todos los órganos de la órganos directivos de la Administración de la Comunidad Autónoma de Extremadura cuya designación corresponda al Consejo de Gobierno por la Ley 8/2011 de Igualdad entre Mujeres y Hombres y contra la Violencia de Género en Extremadura. 
pueden jugar un papel protagonista; en la medida en que no quede garantizada la presencia equilibrada, el establecimiento de cuotas en la composición de los órganos podría ser la solución idónea. Y si la «cultura organizacional» todavía no está «madura» para ello, podría optarse por la inclusión en normas de soft law (planes de RSE, memorias de sostenibilidad...) de cláusulas tipo comply or explain, similares a la Recomendación 14 del Código de Buen Gobierno de las Sociedades Cotizadas $^{51}$, que aconseja que «el consejo de administración apruebe una política de selección de consejeros que [...] promueva el objetivo de que en el año 2020 el número de consejeras represente, al menos, el 30\% del total de miembros del consejo de administración.

También se ha de referir una enmienda del Grupo Parlamentario Socialista (núm. 193) a la ya citada Proposición de Ley para garantizar la igualdad de trato y de oportunidades entre mujeres y hombres en el empleo y la ocupación, que propone la modificación del art. 75 LOIEMH con el siguiente texto: "La composición del consejo de administración de las sociedades obligadas a presentar cuenta de pérdidas y ganancias y de las sociedades cooperativas deberá cumplir con el principio de presencia equilibrada a partir del año 2023». La motivación expresada es la de «equiparar a las cooperativas con el resto de entidades en relación con el cumplimiento del principio de igualdad de trato y de oportunidades entre mujeres y hombres en el empleo y la ocupación». Sin embargo, consideramos que habría que buscar una redacción más ajustada, ya que la interpretación literal de la que se propone podría dar lugar, eventualmente, a que solamente fuese reclamable a las grandes sociedades de capital (obligadas a presentar cuenta de pérdidas y ganancias, entendemos que «no abreviada) mientras que sí lo sería para todas las cooperativas.

Tampoco debería circunscribirse, a nuestro entender, la aplicación del principio de presencia equilibrada al órgano de administración (sea éste colegiado o no52). La mutualidad que caracteriza a la coope-

51 El Código de Buen Gobierno de las Sociedades Cotizadas actualmente vigente en España fue aprobado por la Comisión Nacional del Mercado de Valores en Febrero de 2015 y está accesible en https://www.cnmv.es/DocPortal/Publicaciones/CodigoGov/ Codigo_buen_gobierno.pdf (22/01/19, 12:16). Para un análisis de los altibajos en el fomento de la presencia equilibrada en las sociedades mercantiles españolas ver nuestro trabajo al respecto, «En torno al Informe de impacto de género sobre el Anteproyecto de Código Mercantil».

52 El principio de presencia equilibrada también puede reclamarse para las modalidades unipersonales de órganos de administración, puesto que la LOIEMH lo reconoce explícitamente para órganos o cargos de derecho público de este tipo; es el caso previsto, por ejemplo, en el art. 16 LOIEMH. También se pronuncia en esa línea el Dicta- 
rativa, con la consiguiente obligatoriedad de participación en la actividad cooperativizada, se traduce en una multiplicidad de órganos sociales (intervención, control de la gestión, recursos, liquidadores, comité social, asambleas de sección, juntas preparatorias...) en los que las mujeres han de ver garantizada su presencia equilibrada. Y lo mismo cabría aducir en relación con la estructura técnica o «profesional» de la cooperativa (alta dirección, gerencia, consultoría...).

\section{Combatir la brecha salarial y la retributiva}

En una primera aproximación, el concepto de «brecha salarial» que podemos utilizar para la indagación sobre su existencia en las entidades de la economía social es el de "promedio de la diferencia entre ingresos brutos por hora de hombres y mujeres ante trabajo igual o de igual valor». Las causas que se apuntan para su producción son diversas, pero pueden resumirse, nuevamente, en uno de sus elementos comunes: son los estereotipos de género los que se encuentran en su base. Algunos de ellos son los siguientes: la existencia de segregación horizontal, que hace que los empleos y tareas considerados «femeninos» se conviertan, en general, en menos valorados; la segregación vertical, o «techo de cristal», que dificulta el acceso de las mujeres a los puestos de dirección; la transición entre educación y mercado laboral, en la que las mujeres, aunque más y mejor formadas, siguen encontrando mayores dificultades; las tareas de cuidados, que siguen recayendo fundamentalmente en las mujeres y que condicionan el tipo de contrato (temporal), la duración de la jornada laboral (tiempo parcial, 75\%) y las excedencias y permisos para cuidado de hijos e hijas y otras personas dependientes, y que requieren de más horas de trabajo, no retribuidas ${ }^{53}$; la atribución de «complementos salariales» que, «en unos casos

men del Consejo de Estado, de 22 de junio de 2006, sobre el entonces Anteproyecto de LOIEMH. (p. 19): «La «composición equilibrada» evoca la situación de órganos colegiados [...], mientras que la orientación del Anteproyecto no se limita a un equilibrio en la composición de órganos de tal naturaleza, sino que pretende alcanzar el equilibrio en relación con nombramientos y designaciones de órganos unipersonales y cargos de responsabilidad [...], equilibrio predicable, en este caso, de la presencia de mujeres y hombres «en el conjunto a que se refiera» (utilizando la acertada expresión de la disposición adicional primera)».

53 «Durante 2017 se registraron 55.133 excedencias para cuidar de un hijo, de menores acogidos o de otros familiares y, de ellas, 49.934 (el 90,57\%) fueron solicitadas por mujeres, según datos del Ministerio de Empleo y Seguridad Social. Además, de acuerdo a la Encuesta de Población Activa, en el cuatro trimestre de 2017 había 2 millo- 
se trata de complementos otorgados con criterios discrecionales, sobre todo en los puestos directivos, y que benefician menos a las mujeres», y en otros "retribuyen aspectos "masculinizados" del trabajo, como el esfuerzo físico, la penosidad, la nocturnidad, o la disponibilidad horaria; mientras que no se retribuyen los atributos "feminizados": atención, precisión, resistencia, etc.» (CCOO, 2018:27).

La brecha salarial vulnera la prohibición de discriminación por sexo en la remuneración del trabajo (art. 35.1 CE); el principio de igualdad de trato y de oportunidades entre mujeres y hombres, aplicable en el ámbito del empleo privado y en el del empleo público, que «se garantizará, en los términos previstos en la normativa aplicable, [...] en las condiciones de trabajo, incluidas las retributivas» (art. 5 LOIEMH); y la obligación de la persona empresaria de «pagar por la prestación de un trabajo de igual valor la misma retribución, satisfecha directa o indirectamente, y cualquiera que sea la naturaleza de la misma, salarial o extrasalarial, sin que pueda producirse discriminación alguna por razón de sexo» (art. 28 ET). «A pesar de ello, la brecha salarial entre mujeres y hombres persiste ${ }^{54}$.

Cuando intentamos trasladar dicho análisis a las cooperativas, a fin de comprobar si en ellas se da una mejor situación para las mujeres o si también se reproduce la discriminación salarial de género, nos encontramos con dos dificultades básicas: la primera, ya constatada, la de la falta de datos y estudios en la materia; la segunda, la de tener que diferenciar entre las personas trabajadoras por cuenta ajena y las personas socias trabajadoras o de trabajo, cuyas retribuciones por su prestación de trabajo no tienen la consideración de salario, sino de anticipos a cuenta de beneficios. A la espera de poder contar con datos completos y actualizados, únicamente podemos aportar indicios de que la brecha salarial y retributiva también se dan en las cooperativas.

Por una parte, como ya hemos apuntado supra, de los datos desagregados por sexo que aporta el Ministerio de Empleo español respecto de las personas que trabajan en cooperativas y sociedades laborales, se deduce la existencia de segregación vertical, ya que las mujeres se si-

nes de ocupadas trabajando a tiempo parcial en toda España, frente a un 733.300 hombres en esa situación, menos de la mitad.», EUROPA PRESS, 08/03/2018, "Huelga feminista 2018: la brecha salarial, en ocho gráficos», https://www.europapress.es/sociedad/ noticia-huelga-feminista-2018-brecha-salarial-ocho-graficos-20180306113956.html, 21/01/19, 06:10.

54 «En 2015 [último año del que se cuentan datos], la ganancia media anual de las mujeres era de $20.052 €$ y la de los hombres de $25.993 €$, lo que supone una diferencia de $5.941 €$ y una brecha del $30 \%$; es decir, el salario medio anual de las mujeres tiene que aumentar el 30\% para equipararse al de los hombres» (CCOO, 2018:15 y 16). 
túan mayoritariamente en las categorías profesionales menos retribuidas. Si a ello añadimos que tal situación se contradice con su probable mayor nivel formación y cualificación, cabe sospechar que mujeres capacitadas para ejercer tareas de superior clasificación profesional están siendo relegadas a las peor pagadas. Por otra parte, también se puede constatar la mayor precariedad de la prestación de trabajo de las mujeres en cooperativas y sociedades laborales: a 30/09/18, las mujeres eran el $45,5 \%$ de las personas dadas de alta en estas entidades, y entre ellas un $26,7 \%$ lo eran con contratos temporales, frente al $23,1 \%$ de varones con dicho tipo de contratos. En relación con el trabajo a tiempo parcial, el $32,4 \%$ de las mujeres tenía ese tipo de jornada, mientras que solamente lo hacían el 10,1\% de los hombres ${ }^{55}$. En un sentido similar apunta un reciente trabajo de Pérez y Valiente (2018) sobre el perfil y calidad del empleo generado por las sociedades cooperativas andaluzas, aunque también constata que «las cooperativas generan mayores oportunidades laborales para las mujeres que las sociedades mercantiles».

Por lo demás, no se cuenta en absoluto con datos respecto de la brecha salarial/retributiva para los puestos de alta dirección y para los supuestos de retribución por cargos representativos; pero si fuesen trasladables, aunque solo fuese de manera orientativa, los datos que sí que afloran en el ámbito de las sociedades de capital, cabe sospechar que la discriminación por razón de sexo es todavía mayor ${ }^{56}$.

En cualquier caso, se ha planteado que, mientras que «la discriminación salarial directa entre mujeres y hombres por un trabajo igual es ahora poco frecuente», "las normas antidiscriminatorias por razón de sexo en materia salarial han sido menos eficaces a la hora de garantizar la igualdad retributiva por un trabajo de «igual valor», de forma que en muchas ocasiones pueden concurrir discriminaciones indirectas debido a la ausencia de instrumentos aplicables que permitan determinar cuando estamos ante trabajos de «igual valor» que, consecuentemente, deben ser remunerados de igual modo». Por ello, «la Comisión

55 Ministerio de Trabajo, Migraciones y Seguridad Social: BASE DE DATOS DE LA ECONOMIAA SOCIAL. Características de los Trabajadores en situación de alta en la Seguridad Social. 30 de Septiembre de 2018, http://www.mitramiss.gob.es/es/sec_trabajo/ autonomos/economia-soc/EconomiaSocial/estadisticas/CaracteristicasTrabajadores/2018/ 3TRIM/GRAFICO_3TRIMESTRE.pdf , 21/01/19, 07:31.

56 Los pocos estudios al respecto hablan de brechas salariales y/o retributivas significativamente mayores. Ver, p. e., Raúl Sánchez y Héctor Figueroa: «La brecha salarial en la Bolsa española: las consejeras cobran hasta un $40 \%$ menos que los hombres», eldiario.es, 08/03/18, https://www.eldiario.es/economia/consejeras-brecha-salarialllega_0_747875861.html, 21/01/19, 12:08. 
Europea, en su Recomendación de 7 de marzo de 2014 sobre el refuerzo del principio de igualdad de retribución entre hombres y mujeres a través de la transparencia, ha recomendado a los Estados miembros que precisen en su legislación el concepto de «trabajo de igual valor», en consonancia con la jurisprudencia del Tribunal de Justicia de la Unión Europea.[...] empleando criterios objetivos tales como los requisitos educativos, profesionales y de formación, la cualificación, el esfuerzo y la responsabilidad, la prestación realizada y la naturaleza de las tareas en cuestión ${ }^{57}$

En línea con tal recomendación, el 10 de noviembre de 2017 el Grupo Parlamentario Podemos-En Común y Podem-En Marea presentó una Proposición de Ley de Igualdad Retributiva entre Mujeres y Hombres $^{58}$ en la que se incluyen dos iniciativas para la modificación de la Ley $27 / 1999$, de Cooperativas (LC). Por una parte, se propone modificar el art. 16.1 LC a fin de que en el libre ejercicio de los derechos de las personas socias «en ningún caso se pueda producir discriminación directa o indirecta por razón de sexo.» ${ }^{59}$. Por otra parte, en el art. 80.4 LC en relación con la regulación de los anticipos societarios a percibir por las personas socias trabajadoras se plantea especificar que «Deberá pagarse igual anticipo por la prestación de servicios de igual valor, en todos sus conceptos, sin que pueda producirse discriminación alguna, directa o indirecta, por razón de sexo, en ninguna de las condiciones del anticipo»; así como la adición de un apartado 9 al mismo art. 80 LC, a fin de especificar «el principio de igual retorno cooperativo por trabajo de igual valor realizado por hombres o mujeres, sin que, ni en su cuantía ni en ninguna de sus condiciones, se pueda producir discriminación directa o indirecta por razón de sexo».

Por su parte, la Proposición de Ley para garantizar la igualdad de trato y de oportunidades entre mujeres y hombres en materia retributiva, presentada por el Grupo Parlamentario Socialista, también apunta que «los criterios para determinar la cuantía de los anticipos societarios deberán retribuir igual los trabajos iguales o de igual valor» en el art. 80.4 de la LC. A tal efecto, se considerará que «un trabajo tendrá

57 Proposición de Ley para garantizar la igualdad de trato y de oportunidades entre mujeres y hombres en materia retributiva, presentada por el Grupo Parlamentario Socialista el 02/03/18, http://www.congreso.es/public_oficiales/L12/CONG/BOCG/B/BOCG12-B-214-1.PDF , 21/01/19, 08:23.

58 http://www.congreso.es/public_oficiales/L12/CONG/BOCG/B/BOCG-12-B-171-1. PDF , 21/01/19, 10:11.

59 No parece aportar una mejora significativa esta propuesta, más allá de un efecto «recordatorio» de la prohibición expresada por la propia Constitución española y la LOIEMH. 
igual valor que otro cuando la naturaleza de las actividades efectivamente encomendadas, las condiciones educativas, profesionales o de formación exigidas para su ejercicio, los factores estrictamente relacionados con su desempeño y las condiciones en las que lleva a cabo su prestación en realidad sean equivalentes» ${ }^{60}$. Para las sociedades laborales se proponen dos modificaciones en la Ley 44/2015, de Sociedades Laborales y Participadas (LSLP): que «la transmisión de acciones o participaciones que [...] incurran en discriminación directa o indirecta no producirán efecto alguno frente a la sociedad» (art. 6.4 LSLP); y que «la actuación de los administradores debe [...] favorecer [...] la igualdad de trato y de oportunidades entre hombres y mujeres, en particular en materia retributiva» (art. 13.3 LSLP).

En relación con las sociedades laborales se ha de tener en consideración que también les serían aplicables, en función de sus características particulares, otras propuestas para que las sociedades de capital adopten medidas de transparencia en materia retributiva. En concreto, se ha señalado que "Las medidas que pueden adoptarse para dar cumplimiento al artículo 21.4 de la Directiva 2006/54 pueden diferenciarse en dos tipos: las que revelan la retribución de los empleados individualmente considerados según su sexo ante indicios de discriminación y las que muestran información salarial colectiva para los distintos grupos o categorías profesionales. Las primeras se dirigen fundamentalmente a resolver casos individuales de discriminación salarial y cuentan con un efecto preventivo; las segundas tienen como principal finalidad diagnosticar la existencia de diferencias retributivas injustificadas y emprender medidas más generales encaminadas a eliminarlas».

Para ello, se propone la modificación de la Ley de Sociedades de Capital, en sus artículos 271.4, para recordar que el sistema de remuneración de las personas administradoras «no podrá incurrir en discri-

60 Una enmienda del Grupo parlamentario Ciudadanos propone modificaciones en al respecto, demandando una redacción del artículo 80.4 LC, diferente a la propuesta, en los siguientes términos: "Deberá pagarse igual anticipo por la realización de trabajos de igual valor, en todos sus conceptos, sin que pueda producirse discriminación alguna, directa o indirecta, por razón de sexo, en ninguna de las condiciones del anticipo. A estos efectos, se considerará por trabajo de igual valor la definición establecida en el artículo 28 del Estatuto de los Trabajadores»; y la adición de un apartado 9 al mismo artículo, con una redacción prácticamente idéntica a la ya propuesta por el Grupo Parlamentario Podemos-En Común y Podem-En Marea en su Proposición de Ley de Igualdad Retributiva entre Mujeres y Hombres: «9. Los retornos cooperativos se calcularán tomando en consideración el principio de igual retorno cooperativo por trabajo de igual valor, sin que, ni en su cuantía ni en ninguna de sus condiciones, se pueda producir discriminación directa o indirecta por razón de sexo.». 
minación directa o indirecta por razón de sexo»; y 260, menciones décima, undécima y duodécima, a fin de que se publique en la memoria de estas entidades información desagregada por sexo de sueldos y salarios, cargas sociales, cotizaciones a pensiones, y retribuciones de personas consejeras y de alta dirección. Respecto de éstas dos últimas, se habrán de especificar dietas, obligaciones contraídas en materia de pensiones, primas de seguros de vida o de responsabilidad civil, anticipos y créditos concedidos, y obligaciones asumidas a título de garantía.

\section{Erradicar y prevenir la violencia de género en la actividad económica}

El concepto de violencia de género incluye la violencia económica ${ }^{61}$, que suele asociarse a la que se da en el ámbito privado, doméstico ${ }^{62}$; pero se ha de tener presente que también incluye otras modalidades, dado que en una acepción más amplia incluye, a nuestro entender más acertadamente, "todo acto de fuerza o de poder ejercido contra las mujeres y que vulnera sus derechos económicos» ${ }^{63}$. Además, se apunta que «se pueden distinguir dos variantes en este tipo de agresiones: la violencia económica y la patrimonial. La primera se manifiesta «a través de limitaciones encaminadas a controlar las percepciones económicas de la víctima; puede ser a nivel familiar y también por percibir un menor salario por su condición de género, si hablamos a nivel laboral». En cuanto a la patrimonial, se entiende "que va más enfocada al bien de la persona»; "en este caso se da al ejercer un daño sobre el bien de la mujer o persona, quizá al vender su patrimonio, dañarlo, o privarla

61 NACIONES UNIDAS, Manual de legislación sobre la violencia contra la mujer, en WOMENWATCH, 2010, http://www.un.org/womenwatch/daw/vaw/handbook/ Handbook-for-legislation-on-VAW-\%28Spanish\%29.pdf, 21/01/19, 12:17.

62 La violencia económica se ha definido (suponemos que en el contexto de la Ley Orgánica 1/2004, de 28 de diciembre, de Medidas de Protección Integral contra la Violencia de Género) como «la privación intencionada, y no justificada legalmente, de recursos para el bienestar físico o psicológico de la mujer y de sus hijas e hijos o la discriminación en la disposición de los recursos compartidos en el ámbito de la pareja», Consejería de Igualdad, Salud y Políticas Sociales, Junta de Andalucía,http:// www.juntadeandalucia.es/igualdadybienestarsocial/export/Violencia_Genero/HTML/ Definiciones.html, 21/01/19, 12:20. En el mismo sentido, http://igualdade.xunta.gal/es/ content/que-es-la-violencia-de-genero , 21/01/19, 12:29.

63 Roselia NÚÑEZ, «La violencia económica hacia las mujeres es una realidad», en CENTRO DE ESTUDIOS DE GÉNERO DE LA UNIVERSIDAD DE EL SALVADOR, http:// genero.ues.edu.sv/index.php/reportajes/63-la-violencia-economica-hacia-las-mujeres-esuna-realidad, 22/01/17, 18:17. 
del derecho de tener documentos que son vitales para la compraventa del bien» ${ }^{64}$. Es por ello que entendemos que también puede darse en el ámbito societario, especialmente en las situaciones de subordinación (legal o de hecho, laboral o profesional).

En cualquier caso, frente a cualquier manifestación de violencia de género cabe invocar la tutela del derecho fundamental a la igualdad y la no discriminación que establece la Constitución Española y desarroIla la LOIEMH. En relación con ésta ultima, es de especial aplicación su artículo 7.4: «El condicionamiento de un derecho o de una expectativa de derecho a la aceptación de una situación constitutiva de acoso sexual o de acoso por razón de sexo ${ }^{65}$ se considerará también acto de discriminación por razón de sexo».

En el ámbito del Derecho societario no se había planteado todavía la necesidad de adoptar medidas contra la violencia de género; pero, como hemos visto, algunas leyes cooperativas autonómicas comienzan a referirse a ello (LCAr, art. 59.4; LCG, art. 107, Disp. Ad. Sexta, 5. ${ }^{\circ}$, lo que nos da pié a hacer propuestas en ese sentido. En efecto, consideramos que la extrema gravedad de las conductas violentas y sus terribles consecuencias hacen necesario reclamar que los textos legales reguladores de la actividad empresarial incorporen normas imperativas que ayuden a eliminar en ella la más radical expresión de la discriminación contra las mujeres. Una propuesta al respecto podría ser incluir, como causa legal de exclusión del socio o de despido del trabajador, su condena por un delito de violencia de género hacia mujeres relacionadas con la sociedad, sea como socias, trabajadoras, colaboradoras externas o proveedoras, clientes o usuarias. Además, debería preverse la adopción de medidas cautelares en el funcionamiento societario y empresarial mientras el posible maltratador sea investigado por ello, muy especialmente en los supuestos en que se haya decretado una orden de alejamiento.

En el ámbito opuesto, es de destacar la única norma que conocemos que, en el ámbito societario en general y en el cooperativo en particular, aborda la adopción de «medidas dirigidas a la plena integración laboral y social de las mujeres víctimas de violencia de género». Nos re-

64 Juan TOLENTINO MORALES, eleconomista.com.mx, 07/03/18, «La violencia económica y patrimonial, el enemigo invisible», https://www.eleconomista.com. $\mathrm{mx} /$ finanzaspersonales/La-violencia-economica-y-patrimonial-el-enemigo-invisible20180307-0117.html, 21/01/19, 13:43.

65 Art. 7.2 LOIEMH: "Constituye acoso por razón de sexo cualquier comportamiento realizado en función del sexo de una persona, con el propósito o el efecto de atentar contra su dignidad y de crear un entorno intimidatorio, degradante u ofensivo». 
ferimos a la Disposición adicional sexta, $5 .^{\circ}$ LCG, que efectúa el correspondiente mandato a tanto a la Xunta de Galicia como a las cooperativas gallegas.

Sea como sea, se incorporen o no tales previsiones a los textos legales correspondientes, nada impide incorporar a normas internas estatutarias o de régimen interno la calificación de la violencia de género como falta muy grave sancionable con la expulsión o el despido; los protocolos de prevención y sanción del acoso sexual o por razón de sexo; y medidas de apoyo a las socias y trabajadoras que hayan sido objeto de violencia.

\section{Promover la comunicación inclusiva}

Como se ha indicado, «el español cuenta con una serie de mecanismos mediante los que la discriminación sexual [...] se recrea, se reproduce y se mantiene [...] reflejando, construyendo y naturalizando la concepción sexista de la realidad. Se trata de usos «normales» del español que actúan contra las mujeres y perpetúan la idea de la superioridad masculina. Entre ellos, [...] la ocultación de la mujer en el lenguaje por el empleo reiterado de voces masculinas en sentido genérico [...] y como consecuencia, la identificación de lo masculino con la humanidad»66. Las constatadas consecuencias psicológicas para la identidad femenina de este proceso de exclusión de la lengua, de no ser nombrada, así como el grado de confusión e inseguridad jurídica que puede generar el uso del masculino genérico, han llevado, reiteradamente, a la intervención de las instituciones públicas ${ }^{67}$.

En relación con ello, el Consejo de Europa ha reconocido que «la utilización masiva de formas masculinas para referirse a hombres y mujeres, por una parte, afecta a su identidad (a los unos los supravalora, al nombrarlos constantemente y convirtiéndolos en protagonistas únicos,

66 Mercedes BENGOECHEA BARTOLOMÉ, "Lección 3. Lenguaje y sexismo», en VV.AA., Diversidad de género e igualdad de derechos, (coord. Carmona) [Tirant lo Blanch], 2012, pp. 42 y 43.

67 Por ejemplo, ya en 2011, la Comisión de Igualdad del Consejo General del Poder Judicial promovió la investigación que dio lugar a la publicación de WV.AA., Lenguaje jurídico y género: sobre el sexismo en el lenguaje jurídico (coords. Ana Rubio y Encarna Bodelón), Consejo General del Poder Judicial, Madrid, 2011, pp. 8 y 9, http://www.poderjudicial.es/stfls/CGPJ/OBSERVATORIO\%20DE\%20VIOLENCIA\%20 DOM\%C3\%89STICA/ESTUDIOS/FICHERO/20131129\%20Libro\%20completo\% 20 Lenguaje\%20Jur\%C3\%ADdico\%20y\%20de\%20G\%C3\%A9nero.pdf, 21/01/19, $14: 14$. 
a las otras las ignora) y, por otra parte, repercute en la desigualdad social». También la UNESCO, desde los años 80, urge «en primer lugar a nombrar a las mujeres y sus experiencias, y en segundo lugar a utilizar un lenguaje neutral». En el Estado español, la Ley Orgánica de Igualdad establece diversas vías de introducción del lenguaje no sexista, entre las cuales interesa ahora la introducción, entre los criterios generales de actuación de los poderes públicos, de «la implantación de un lenguaje no sexista en el ámbito administrativo». Fruto de ello son algunos textos legales que, como veremos, van incorporándolo en su misma redacción o las Normas mínimas para evitar la discriminación de la mujer en el lenguaje administrativo elaboradas por el Consejo General del Poder Judicial en 200968.

Por el contrario, la mayor parte de los textos legales reguladores de las personas jurídicas empresariales, incluyendo los de las cooperativas, adolecen del exclusivo uso de genéricos masculinos: el "empresario», «los apoderados», "los administradores», "los socios», "los accionistas» «los fundadores», «el notario autorizante», "el registrador mercantil», «los consejeros», «los obligacionistas», «el auditor», «los acreedores», «los liquidadores», «los contratantes», «el vendedor», «el comprador», «el contratista», «el comisionista», «el portador»... y un sinfín más. Frente a ello, las recomendaciones para la práctica del lenguaje no sexista incluyen: preferir el uso de palabras o términos no sexuados, es decir, sin variación por el género, utilizar términos colectivos, abstractos, expresiones equivalentes, la forma femenina y masculina, las barras, la arroba... escogiendo, cuando hayan varias opciones, la mas sencilla de leer.

Es una satisfacción constatar que diversas leyes cooperativas del Estado español han ido incorporando el lenguaje inclusivo en su redacción. Es el caso de las Leyes de cooperativas de la Comunidad de CastiIla-La Mancha, de la Comunidad Valenciana, de Galicia y de Andalucía. También parece llegado el momento de que las propias entidades de la economía social comiencen a adoptarlo, tanto en su comunicación interna como externa, con especial incidencia en las campañas publicitarias y promocionales que se puedan desarrollar.

68 Consejo General del Poder Judicial, Comisión de Igualdad: Normas mínimas para evitar la discriminación de la mujer en el lenguaje administrativo, http://www. poderjudicial.es/cgpj/es/Temas/Igualdad-de-Genero/Normas-minimas-lenguaje-inclusivo/, 21/01/19, 14:24. 


\section{Bibliografía}

Alonso Álvarez, Alba; Diz Otero, Isabel; y Lois GonzÁlez, Marta: «La influencia de las políticas públicas de igualdad en la toma de decisiones: un análisis de los informes de impacto de género», Revista Española de Ciencia Política, núm. 24, diciembre de 2010, pp. 107-136.

Carretero, María José; Avello, Goretti; Fundación Mujeres: La participación de las mujeres en las cooperativas agrarias. Estudio de diagnóstico y análisis acerca de las barreras para la participación de las mujeres en los órganos de gestión de las cooperativas del sector agroalimentario, Proyecto Integra, Ministerio de Agricultura, Alimentación y Medio Ambiente, FEADER y Cooperativas Agro-alimentarias de España, 2011, http://www.prodetur. es/prodetur/AlfrescoFileTransferServlet?action=download\&ref=8076511d9d1d-4134-bef1-ff6e897db3bf, 20/01/19, 12:23.

CCOO, Secretaría Confederal de Mujeres e Igualdad: La brecha salarial, factor de quiebra democrática, CCOO, 2018, http://www.ccoo.es/a5c08c3a0907041e31b6c3056ab1b07a000001.pdf, 21/01/19, 06:30.

COCETA, Estudio sobre la realidad social y laboral de las mujeres en el Cooperativismo de trabajo asociado en España, Confederación Española de Cooperativas de Trabajo Asociado, 2004, http://www.coceta.coop/mujercooperativas-trabajo.asp, 20/01/19, 16:09.

Delso, Ana Isabel: "Más allá de la igualdad: género y cooperativismo», Cuadernos Mujer y Cooperativismo, núm. 3, 2001, http://www.coceta.coop/ cuadernos-mujer-cooperativismo/Tercero/textos/articulo02.htm, 20/01/19, 16:01.

Elıo Cemborain, Eunate: «Responsabilidad social en las cooperativas: igualdad de oportunidades entre hombres y mujeres», GEZKI, núm. 2, 2006, pp. 35-71, https://www.google.com/url?sa=t\&rct=j\&q=\&esrc=s\&source=we b\&cd=5\&ved=2ahUKEwiUq62hj_XfAhWHHhQKHb7SDLYQFjAEegQIBhAC\& url=http\%3A\%2F\%2Fwww.ehu.eus\%2Fojs\%2Findex.php\%2Fgezki\%2Far ticle\%2Fdownload\%2F3292\%2F2918\&usg=AOvVaw2dkS5c1_c9jTPNXPE1 AbTr, 21/01/19, 14:57.

- «Techo de cristal y escalera de cristal en las cooperativas de Mondragón. Participación de las mujeres en los órganos de gobierno de las cooperativas», First International CIRIEC-Research Conference on the Social Economy, Strengthening and Building Communities: The Social Economy in a Changing World, October 22-25, 2007, Victoria, BC, Canadá, https://docplayer.es/26802543-Techo-de-cristal-y-escalera-de-cristal-en-lascooperativas-de-mondragon-participacion-de-las-mujeres-en-los-organosde-gobierno-de-las-cooperativas.html, 21/01/19, 15:02.

- «La igualdad en el gobierno cooperativo: Participación de las mujeres en las cooperativas de Mondragon», Semana Europea de la Calidad y la Excelencia 2016, 15 de noviembre de 2016, Bilbao, http://www. emakunde.euskadi.eus/contenidos/informacion/formacion_trabajo/es_def/ adjuntos/2016.11.15.eunate_elio.pdf, 20/01/19, 13:16. 
EMAKUNDE-Instituto VASCo DE LA Mujer, Informe relativo al Proyecto de Ley de Cooperativas de Euskadi, 26 de octubre de 2015, http://www.euskadi. eus/contenidos/proyecto_ley/xleg_pyley_10/es_pyley_10/adjuntos/10.\%20 Ley\%20de\%20Cooperativas\%20de\%20Euskadi/informe\%20emakunde. pdf, 20/01/19, 16:43.

- Informe relativo al Proyecto de Ley de Cooperativas de Euskadi, 27 de marzo de 2018, http://www.euskadi.eus/contenidos/proyecto_ley/28_ pley_xileg/eu_def/adjuntos/Informe\%20Emakunde.pdf, 20/01/19, 16:43.

emakUnde-Instituto Vasco de la Mujer, Gobierno Vasco, Helena Ortiz de LeJARAZU-RED KUORUM: Guía para la elaboración de informes de impacto de género, 2013, Emakunde-Instituto Vasco De La Mujer, http://www. emakunde.euskadi.eus/contenidos/informacion/pub_guias/es_emakunde/ adjuntos/26.guia.para.la.elaboracion.de.informes.de.impacto.de.genero. pdf, 20/01/19, 17:03.

Esteban Salvador, M. ${ }^{a}$ Luisa; Gargallo Castel, Ana F.; Pérez Sanz, Francisco J.: «Composición del consejo rector y género en las cooperativas turolenses», REVESCO, núm. 101, primer cuatrimestre, 2010, pp. 7-27, http://revistas. ucm.es/index.php/REVE/article/view/REVE1010230007A, 20/01/19, 13:19.

- «El papel de la mujer en las cooperativas agrícolas turolenses», CIRIECEspaña, Revista de Economía Pública, Social y Cooperativa, núm. 748, abril de 2012, pp. 177-205, https://www.redalyc.org/articulo. oa? id=17423124007, 20/01/19, 12:56.

- « ¿Presentan las cooperativas contextos favorables para la igualdad de género?: Especial referencia a la provincia de Teruel», CIRIEC-España, Revista de Economía Pública, Social y Cooperativa, núm. 88, diciembre de 2016, pp. 61-92, https://www.redalyc.org/pdf/174/17449696003.pdf, 20/01/19, 12:56.

- "Áreas rurales y cooperativas: iniciativas de mujeres para el desarrollo», REVESCO, Revista de Estudios Cooperativos, 2018, Primer Cuatrimestre, núm. 127, pp. 116-138, https://revistas.ucm.es/index.php/REVE/article/ view/58397, 21/01/19, 15:08.

FEVECTA (1999), "Las mujeres directivas en las cooperativas de FVECTA», Cuadernos Mujer y Cooperativismo, núm. 1, Noviembre 1999, http://www. coceta.coop/cuadernos-mujer-cooperativismo-1999.asp, 20/01/19, 16:011

HERNÁNDEZ AGUILAR, Orisel, «La relación género y cooperativa en el ordenamiento jurídico cubano. Una aproximación a su realidad y a sus perspectivas ante el proceso de perfeccionamiento del modelo económico en el país», Boletín de la Asociación Internacional de Derecho Cooperativo, núm. 46/2012, Bilbao, pp. 297-320, http://dx.doi.org/10.18543/baidc-462012pp297-320, 20/01/19, 14:12.

Hernández Ortiz, María Jesús; Ruiz Jiménez, Carmen; García Martí, Elia; Pedrosa ORTEGA, Cristina: "Situación actual de la igualdad de género en los órganos de gobierno de las sociedades cooperativas agroalimentarias», REVESCO, Revista de Estudios Cooperativos, vol. 129, 2018, pp. 66-83, https:// revistas.ucm.es/index.php/REVE/article/view/61933/4564456548360, 20/01/19, 13:39. 
International CoOperative Alliance: The International Co-operative Alliance statement on the co-operative identity. The co-operative principles.-Declaración de la Alianza Cooperativa Internacional sobre la identidad cooperativa. Los principios cooperativos, 3. ${ }^{\text {a }}$ ed., Consejo Superior de Cooperativas de Euskadi, 1995.

LÓPEZ I MORA, Frederic: «Problemática laboral de los socios trabajadores de las empresas de economía social. ¿Socios o trabajadores?», CIRIEC, Revista de Economía Pública, Social y Cooperativa, núm 31, 1999, p. 17, http://www. ciriec-revistaeconomia.es/banco/01_Lopez_31.pdf, 20/01/19, 18:43.

LousAdA AROCHENA, José Fernando: "El informe sobre el impacto de género en la elaboración normativa», La Ley, núm. 6092, 23/09/2004, págs. 1-4; y Aequalitas: Revista jurídica de igualdad de oportunidades entre mujeres y hombres, núm. 15, págs. 39-46, http://dialnet.unirioja.es/ descarga/articulo/1335755.pdf, 22/01/19, 15:51, http://www.ccoo.es/ ee347b2e310ece737f62dab7a9293193000001.pdf, 22/01/19, 15:51.

Martínez León, Inocencia María; ArCas Lario, Narciso y García Hernández, Margarita: "La influencia del género sobre la responsabilidad social empresarial en las entidades de economía social», REVESCO, núm. 105, MONOGRÁFICO: La economía social y la igualdad de género, 2011, pp. 143-172, http://revistas.ucm.es/index.php/REVE/article/view/36654/35493 , 21/01/19, 15:37.

Mateos de Cabo, Ruth; Iturriuz del Campo, Javier y Gimeno Nogués, Ricardo: «Aplicación del análisis discriminante al papel de la mujer en los consejos de administración: El caso de las sociedades cooperativas», Comunicación presentada al XXI Congreso Anual AEDEM, Universidad Rey Juan Carlos, Madrid, días 6, 7 y 8 de junio de 2007, vol. 1, 2007 (Ponencias), pp. 53, https://dialnet.unirioja.es/descarga/articulo/2519583.pdf, 20/01/19, 13:26.

Melía Martí, Elena; Carnicer Andrés, María Pía; Juliá Igual, Juan Francisco: «El papel de las mujeres en los órganos de gobierno y su relación con el rendimiento: el caso de las mayores cooperativas agroalimentarias españolas», XI Congreso de la Asociación Española de Economía Agraria, Universidad Miguel Hernández, Orihuela-Elche, 13-15/09/2017, pp. 252-254.

Palomo Zurdo, Ricardo; García Centeno, Carmen; Gutiérrez Fernández, Milagros; y Fernández Barberis, Gabriela: «Responsabilidad social corporativa y género en los consejos de administración de las cooperativas de crédito españolas», Prisma Social, Revista de Ciencias Sociales, núm. 10, 2013, pp. 332-360, https://dialnet.unirioja.es/descarga/articulo/4694892.pdf， 21/01/19, 16:13.

PÉREZ, Omar: "Género y Cooperativas una perspectiva desde la masculinidad», Revista Nueva Luna, núm. 7, Vol. 1, noviembre 1996, Revista del Programa Género en Cooperativas-GEC de la Alianza Cooperativa Internacional-ACl, https://www.idelcoop.org.ar/sites/www.idelcoop.org.ar/files/revista/articulos/pdf/97021703.pdf, 17/01/19, 16:42.

Pérez González, María del Carmen; Valiente Palma, Lidia: «Aproximación al perfil y calidad del empleo generado por las sociedades cooperativas andaluzas», REVESCO, Revista de Estudios Cooperativos, próxima aparición, 
2019, https://revistas.ucm.es/index.php/REVE/article/view/60989, 20/01/19, 14:06.

PousADA, Teresa H.: Género y cooperativas. La participación femenina desde un enfoque de género, Parte 2, Cuaderno de trabajo núm. 19, Ediciones del Instituto Movilizador de Fondos Cooperativos, Ciudad de Buenos Aires, Argentina, 2003, http://www.centrocultural.coop/modules/wfdownloads/ singlefile. php?cid=3\&lid=49, 22/01/17, 16:46

Ribas Bonet, María Antonia; SAJARdo Moreno, Antonia: «La Desigual Participación de Hombres y Mujeres en la Economía Social: Teorías Explicativas», CIRIEC-España, Revista de Economía Pública, Social y Cooperativa, núm. 50, 2004, pp. 77-103, http://www.ciriec-revistaeconomia.es/ banco/04_Sajardo_y_Ribas_50.pdf, 21/01/19, 16:30.

- «Desigualdad de género en tiempos de crisis: Análisis comparativo de la economía social», REVESCO, núm. 105, MONOGRÁFICO: La economía social y la igualdad de género, 2011, pp. 34-56, http://revistas.ucm.es/index. php/REVE/article/view/36650/35489, 21/01/19, 16:30.

RodríGUez GonzÁlez, Amalia, «El órgano de administración de las sociedades laborales», en VV. AA., Participación de los trabajadores en la empresa. Las sociedades laborales y participadas (dir., Gemma Fajardo), Tirant lo Blanch, 2018, pp. 883-909.

SAJARdo Moreno, Antonia; BAKAIKOA AzURmendi, Baleren: «Introducción al monográfico «Economía Social y género»», CIRIEC-España, Revista de Economía Pública, Social y Cooperativa, núm. 50, noviembre 2004, pp. 7-9, http:// www.ciriec-revistaeconomia.es/banco/00_introduccion_50.pdf, 21/01/19, 16:34.

SENENT VIDAL, María José: "¿Cómo pueden aprovechar las cooperativas el talento de las mujeres? Responsabilidad social empresarial e igualdad real», REVESCO, Revista de Estudios Cooperativos, vol. 105, 2011, pp. 57-84, http://revistas.ucm.es/index.php/REVE/article/view/36651, 21/01/19, 16:36.

- «El género en la responsabilidad social empresarial. Especial incidencia en las acciones positivas de buen gobierno corporativo», en VV.AA. (2012), Empresa responsable y crecimiento sostenible (Dir. A. Fernández-Albor; coord. E. Pérez Carrillo), monografía de la Revista de Derecho de sociedades, Editorial Aranzadi, pp. 155-208.

- «La Ley de titularidad compartida de las explotaciones agrarias y sus potenciales efectos jurídicos en las entidades de economía social», CIRIECEspaña, Revista Jurídica de Economía Social y Cooperativa, núm. 23, diciembre de 2012, pp. 179-203, http://ciriec-revistajuridica.es/wp-content/ uploads/023-007.pdf, 20/01/19, 20:22

- «En torno al informe de impacto de género sobre el anteproyecto de código mercantil de 2014», Revista de Derecho Mercantil, núm. 298, octubre-diciembre de 2015, pp. 25-47.

- «Aspectos de la perspectiva de género en la regulación jurídica de las cooperativas», en VV.AA., O Pensamento Feminino na Construção do Direito Cooperativo, (Coords. Marianna y Marilia Ferraz Teixeira), Vincere Editora, Brasilia, 2017. 
— «Los informes de impacto por razón de género como herramientas para la mejora de la legislación de la economía social», en VV.AA., Relaciones de la economía social y solidaria para una sociedad más inclusiva y sostenible y su vinculación con sus orígenes, el derecho y el desarrollo, Universidad de Costa Rica, 2018, pp. 315-324.

Senent VidAL, María José; García CAmpÁ, Santiago, "iMis soci@s no me dejan conciliar!. El derecho a la conciliación de la vida familiar y laboral en las sociedades cooperativas. Comentario a la sentencia del Tribunal de Justicia de la Unión Europea (Sala Segunda) de 16 de junio de 2016», en Cooperativismo e Economia Social, núm. 38, curso 2015/2016, pp. 193-220.

StAFF WILSON, Mariblanca: «La perspectiva de género desde el Derecho», 2000, http://www.legalinfo-panama.com/articulos/articulos_21a.htm 17/01/19, 17:17.

ULSHOEFER, Petra: «Recomendaciones de la OIT con respecto a la igualdad de oportunidades para la mujer trabajadora en el sector cooperativo y de empresas asociativas», II Conferencia nacional sobre la mujer y el movimiento cooperativo en el Perú, Lima, 1991, http://www.sidalc.net/cgi-bin/wxis. exe/?IsisScript=BIBLIOPE.xis\&method=post\&formato=2\&cantidad=1 \&expres ion $=m f n=030665,22 / 01 / 19,15: 54$.

VÁzQuez, Inés; Pousada, Teresa: "La participación de la mujer en los movimientos sociales y en el movimiento cooperativo», Revista Idelcoop, 2000, vol. 27, núm. 128, pp. 414-441, https://www.idelcoop.org.ar/sites/www. idelcoop.org.ar/files/revista/articulos/pdf/2000_259966309.pdf, 17/01/19, 16:59.

VilLafÁñez Pérez, Itziar: «Principios y valores cooperativos, igualdad de género e interés social en las cooperativas», CIRIEC, Revista jurídica de Economía social y cooperativa, núm. 30, junio 2017, http://ciriec-revistajuridica.es/ revista/30/, 17/01/19, 18:14.

VV.AA. (coords.: Meliá Martí, Elena; Carnicer Andrés, María Pía; Juliá Igual Juan Francisco): El gobierno de las sociedades cooperativas agroalimentarias españolas. Modelos de referencia y casos empresariales, Cajamar Caja Rural, 2017, http://www.publicacionescajamar.es/pdf/seriestematicas/informes-coyuntura-monografias/el-gobierno-de-las-sociedades. pdf, 20/01/19, 13:56. 